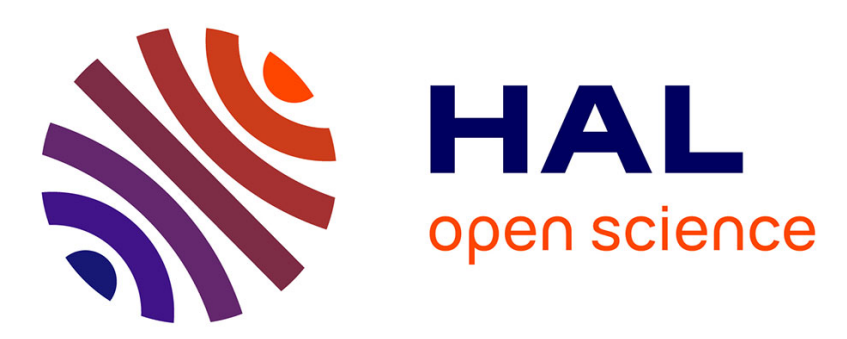

\title{
Comparison of sediment transport formulae for a coastal environment
}

B. Camenen, Philippe Larroudé

\section{To cite this version:}

B. Camenen, Philippe Larroudé. Comparison of sediment transport formulae for a coastal environment. Coastal Engineering, 2003, 48, pp.111-132. 10.1016/S0378-3839(03)00002-4 . hal-00259797

\section{HAL Id: hal-00259797 \\ https://hal.science/hal-00259797}

Submitted on 25 Feb 2020

HAL is a multi-disciplinary open access archive for the deposit and dissemination of scientific research documents, whether they are published or not. The documents may come from teaching and research institutions in France or abroad, or from public or private research centers.
L'archive ouverte pluridisciplinaire HAL, est destinée au dépôt et à la diffusion de documents scientifiques de niveau recherche, publiés ou non, émanant des établissements d'enseignement et de recherche français ou étrangers, des laboratoires publics ou privés.

\section{(c)(1)}

Distributed under a Creative Commons Attribution| 4.0 International License 


\title{
Comparison of sediment transport formulae for the coastal environment
}

\author{
Benoît Camenen*, Philippe Larroudé \\ Laboratoire des Ecoulements Géophysiques et Industriels, Institut de Mecanique de Grenoble, BP51, 38041 Grenoble cedex 9, France
}

\begin{abstract}
Most existing sediment transport formulae to estimate transport rate in the coastal environment have a restricted range of applicability and are often used beyond this range. The aim of this paper is to investigate the limits of five of these formulae: the Bijker, Bailard, Van Rijn, Dibajnia and Watanabe, and Ribberink formulae. The sensitivity of these formulae to wave orbital velocity, wave period, wave asymmetry, sediment grain size, and steady current has been studied and tested against data for large velocities where significant errors can appear. The formulae behave in very different ways if one of the main parameters is slightly modified, particularly when fine sediments are present and phase-lag effect appears. But important discrepancies between formulae can also be observed for medium sand. At last, the wave-related sediment transport (due to wave asymmetry) has great importance for the morphodynamic and is only accounted for in the Bailard, Dibajnia and Watanabe, and Ribberink formulae.
\end{abstract}

Keywords: Sediment transport models; Coastal environment; Sediment grain size; Orbital velocity; Wave asymmetry; Steady current

\section{Introduction}

Calculating nearshore sediment transport is a challenge due to the complexity of the hydrodynamics and the variety of the governing phenomena. Indeed, it is very difficult to estimate sediment fluxes on beaches due to the combination of steady flows (currents) and oscillatory flows (waves). Moreover, many other effects should be integrated such as the variations in mean water level (tide, set-up, and set-down), breaking wave effects (turbulence and undertow), and topographic influence (mean slope and bed forms).

* Corresponding author. Tel.: +33-4-76-82-50-68; fax: +33-476-82-52-71.

E-mail address: camenen@hmg.inpg.fr (B. Camenen).
Furthermore, these parameters induce different types of transport (bed load, suspended load, and sheet flow), with very different physical implications for the movement of sand.

Many different formulae are available to estimate sediment transport on beaches, most of them based on a macroscopic approach to the phenomena. Two main approaches to the phenomena have been studied: an energetics approach developed by Bagnold (1963) and a probabilistic approach introduced by Einstein (1972). One limitation of the formulae is that authors have mainly compared and fitted their formulae only to a certain set of data (experimental or field data). For example, Bijker (1968), Bailard (1981), and Bailard and Inman (1981) mainly compared their formula to field data for littoral drift; Van Rijn (1984, 1989) 
compared his formula to a large variety of field data; Dibajnia and Watanabe (1992), Dibajnia (1995), Ribberink (1998), and Ribberink and Al Salem (1994) compared and fitted their formula to experimental flume data, Soulsby (1995) compared Bailard formula with data and models.

Apart from the authors, it seems that very few studies have compared the behaviour of different formulae with respect to the main parameters. King and Seymour (1982) performed some comparisons of models with Shields parameter. More recently, DohmenJanssen (1999) compared the Bailard, Ribberink, and Dibajnia and Watanabe formulae with experimental flume data involving different grain sizes, currents, and orbital velocities. Camenen and Larroudé (2000) pointed out the great dependence of sediment fluxes on these parameters. At last, one aim of the Sedmoc program was to find (or improve) a formula, which gives the best results in the nearshore environment. Several authors have hence made some comparisons but only between their own formula and one other, or have only studied the influence of one parameter (see the book resulting from the Sedmoc project, (Van Rijn et al., 2001), papers CJ, CK and CL).

The idea of comparing the dependence of formulae with respect to the main parameters of sediment transport is very interesting. It provides a better understanding of the physics of sediment transport. These parameters relate to wave (bottom orbital velocity, period, and asymmetry), current, and sediment (grain size).

\section{The sediment transport formulae studied}

We chose to study five formulae which are interesting because of their different approaches to the problem:

- The Bijker (1968) and Van Rijn $(1984,1989)$ total load formulae. The formulation for bed load transport comes from a method used in a river environment and adapted to a coastal environment. Suspended load is obtained from the integration over depth of $c(z) v(z)$, where $c$ is the concentration of sediment and $v$ the velocity at level $z$.

- The Bailard (1981) total load formula, which is an energetics formulation for sediment transport due to waves.
- The Dibajnia and Watanabe (1992) total load formula, which results from an analysis of the instantaneous velocity due to wave and current interaction and the associated induced movement of sediment.

- The Ribberink (1998) bed load formula, which is a quasi-steady model of sediment transport that uses instantaneous shear stresses.

\subsection{Bijker formula}

One of the first sediment transport formulations that is still often used in engineering applications was proposed by Bijker (1968). It is derived from Frijlink (1952) formula for a current only with a modification of the bottom shear stress using a wave-current model. The direction of sediment fluxes is always that of the current since this formula was proposed to estimate longshore transport rate:

$q_{\mathrm{sb}}=C_{\mathrm{b}} d \sqrt{\frac{\mu_{\mathrm{c}} \tau_{\mathrm{c}}}{\rho}} \exp \left(-0.27 \frac{\left(\rho_{\mathrm{s}}-\rho\right) g d}{\mu_{\mathrm{c}} \tau_{\mathrm{cw}}}\right)$,

$q_{\mathrm{ss}}=1.83 q_{\mathrm{sb}}\left(I_{1} \ln \left[\frac{33 h}{\delta_{\mathrm{c}}}\right]+I_{2}\right)$,

where $q_{\mathrm{sb}}, q_{\mathrm{ss}}$ : sediment volume fluxes for bed load and suspended load, respectively; $d$ : median grain size diameter; $h$ : water depth; $C_{\mathrm{b}}$ : breaking wave parameter; $\mu_{\mathrm{c}}$ : ripple parameter; $\tau_{\mathrm{c}}$ : shear stress due to current only; $\tau_{\mathrm{cw}}$ : shear stress due to wave-current interaction; $\rho_{\mathrm{s}}, \rho$ : sediment and water densities, respectively; $I_{1}, I_{2}$ : Einstein integrals (suspended load); and $\delta_{\mathrm{c}}=100 \mathrm{~d} / \mathrm{h}$ : dimensionless thickness of the bed load layer.

The ripple parameter introduced by Bijker (1968) is defined by the following equation:

$\mu_{\mathrm{c}}=\left(\frac{f_{\mathrm{ct}}}{f_{\mathrm{c}}}\right)^{3 / 2}$

where $f_{\mathrm{ct}}$ : the total friction coefficient due to current and $f_{\mathrm{c}}$ : the skin friction coefficient due to current. 
The breaking wave coefficient is defined by:

$$
\begin{aligned}
C_{\mathrm{b}} & =2 & & \text { if } H_{\mathrm{w}} / h<0.05 \\
& =2+3\left(H_{\mathrm{w}} / h-0.05\right) & & \text { if } 0.05<H_{\mathrm{w}} / h<0.4 \\
& =5 & & \text { if } 0.4<H_{\mathrm{w}} / h
\end{aligned}
$$

where $H_{\mathrm{w}}$ : wave height and $h$ : water depth.

The shear stress due to the wave-current interaction is computed following the method proposed by Bijker introducing a suspension factor:

$$
\tau_{\mathrm{cw}}=\left[1+0.5\left(\xi_{\mathrm{B}} \frac{U_{\mathrm{w}}}{U_{\mathrm{c}}}\right)^{2}\right] \tau_{\mathrm{cf}}
$$

with $\xi_{\mathrm{B}}=\sqrt{f_{\mathrm{wt}} / f_{\mathrm{ct}}}$ : parameter due to the wavecurrent interaction, $f_{\mathrm{wt}}$ : the total friction coefficient due to waves, $U_{\mathrm{w}}$ : peak value of the wave orbital velocity at the bottom, and $U_{\mathrm{c}}$ : mean current velocity.

The Einstein integrals for the suspended load are given:

$I_{1}=\int_{\delta}^{1}\left(\frac{1-y}{y}\right)^{A} \mathrm{~d} y$,

$I_{2}=\int_{\delta}^{1}\left(\frac{1-y}{y}\right)^{A} \ln y \mathrm{~d} y$.

where $A=W_{\mathrm{s}} / \kappa\left(\tau_{\mathrm{cw}} / \rho\right)^{0.5}$ is a function determining the rate of the suspension, $\kappa=0.41$ is the Von Karman constant, and $W_{\mathrm{s}}$ the settling velocity.

\subsection{Bailard formula}

Bagnold (1966) introduced the energetics model in which the main idea is that the sediment flux is proportional to the energy flux (local rate of energy dissipation). His transport model also separated the two classical types of transport:

- bed load transport sustained by the bed via grain to grain interaction,
- suspended load transport sustained by the current via turbulent diffusion.

Thus, the transport is expressed as:

$q_{\mathrm{s}}=q_{\mathrm{sb}}+q_{\mathrm{ss}} \propto \Omega$

$\Omega=0.5 \rho f_{\mathrm{cw}}|\overrightarrow{u(t)}|^{3}$

with $\Omega$ : energy flux due to waves and currents, $f_{\mathrm{cw}}$ : friction coefficient due to the wave-current interaction, $\overrightarrow{u(t)}$ : instantaneous velocity vector, $\overrightarrow{u(t)}=\overrightarrow{U_{\mathrm{c}}}+$ $\overrightarrow{u_{\mathrm{w}}(t)}, U_{\mathrm{c}}$ : current velocity averaged over the depth, and $u_{\mathrm{w}}(t)$ : instantaneous wave velocity.

The Bailard (1981) formula is derived directly from the Bagnold model. It can take into account wave-current instantaneous velocity profiles. For a horizontal bed, it can ultimately be written as a vector of sediment volume transport:

$\vec{q}_{\mathrm{s}}=\frac{0.5 f_{\mathrm{cw}}}{g(s-1)}\left(\frac{\epsilon_{\mathrm{b}}}{\tan \phi}\left\langle|\vec{u}|^{2} \vec{u}\right\rangle+\frac{\epsilon_{\mathrm{s}}}{W_{\mathrm{s}}}\left\langle|\vec{u}|^{3} \vec{u}\right\rangle\right)$

where $\epsilon_{\mathrm{b}}, \epsilon_{\mathrm{s}}$ : bed load and suspended load efficiencies respectively, $\phi$ : friction angle of the sediment, and \langle\rangle : average over several periods of the wave.

The bed load and suspended load efficiency coefficients are slightly different from those given by Bagnold. Bailard suggested from a calibration with field data that $\epsilon_{\mathrm{b}}=0.1$ and $\epsilon_{\mathrm{s}}=0.02$. One difficulty for this formulation is the estimation of the friction coefficient due to the wave-current interaction as Bailard did not specify any expression for this friction factor. A discussion on this problem is presented in Section 3.1.

\subsection{Van Rijn formula}

The Van Rijn (1989) formula is expressed in the same way as the Bijker formula, as the sum of bed load transport (taking into account the influence of waves) and the suspended load flux integrated over depth. The direction of sediment fluxes is also that of 
the current. Bed load transport can be written as follows:

$q_{\mathrm{sb}}=0.25 d D_{*}^{-0.3}\left(\frac{\tau_{\mathrm{cf}}}{\rho}\right)^{0.5}\left(\frac{\tau_{\mathrm{cw}}-\tau_{\mathrm{cr}}}{\tau_{\mathrm{cr}}}\right)^{1.5}$

where $D_{*}=\left((s-1) g d^{3}=v^{2}\right)^{1 / 3}$ : dimensionless sediment diameter, $\tau_{\mathrm{cf}}=\mu_{\mathrm{c}} \alpha_{\mathrm{cw}} \tau_{\mathrm{c}}$ : total shear stress due to current only (taking into account the influence of bed forms), $\tau_{\mathrm{cr}}$ : critical shear stress for sediment transport, $\mu_{\mathrm{c}}=f_{\mathrm{c}} / f_{\mathrm{ct}}$ : shape factor, and $\alpha_{\mathrm{cw}}$ : coefficient due to the presence of waves (which can affect the mean shear stress).

Suspended load transport is computed by solving the equation of concentration over depth:

$\frac{\mathrm{d} c}{\mathrm{~d} z}=-\frac{(1-c)^{5} c W_{\mathrm{s}}}{\epsilon_{\mathrm{scw}}}$

where $c(z)$ : mean volume concentration (time averaged) at height $z,(1-c)^{5}$ corresponds to the decrease of the settling velocity due to high concentrations, and $\epsilon_{\text {scw }}$ : mixing coefficient in case of a wave-current interaction.

Then, integrating sediment fluxes over depth:

$q_{\mathrm{ss}} \int_{a}^{h} \overline{u(z)} c(z) \mathrm{d} z$

where $h$ : water depth; $a=\max \left(k_{\mathrm{sct}}, k_{\mathrm{swt}}\right)$ : reference level; $k_{\text {sct }}, k_{\text {swt }}$ : total roughness values due to current and waves; and $\overline{u(z)}$ : mean velocity (time averaged) at height $z$.

$\epsilon_{\mathrm{scw}}, c_{\mathrm{a}}$ and $\overline{u(z)}$ are computed following the equations given by Van Rijn $(1984,1989)$.

\subsection{Dibajnia and Watanabe formula}

Another interesting sediment transport formulation is that of Dibajnia and Watanabe (1992) and Dibajnia (1995). Similar to the Bailard and Ribberink models, it breaks down the sediment transport into two halfcycles due to the presence of waves (cf. Fig. 1). During the first half-cycle, sediment moves in the direction of the wave, just as it moves in the opposite direction during the second half-cycle. An interesting aspect of the formula is that it takes into account a

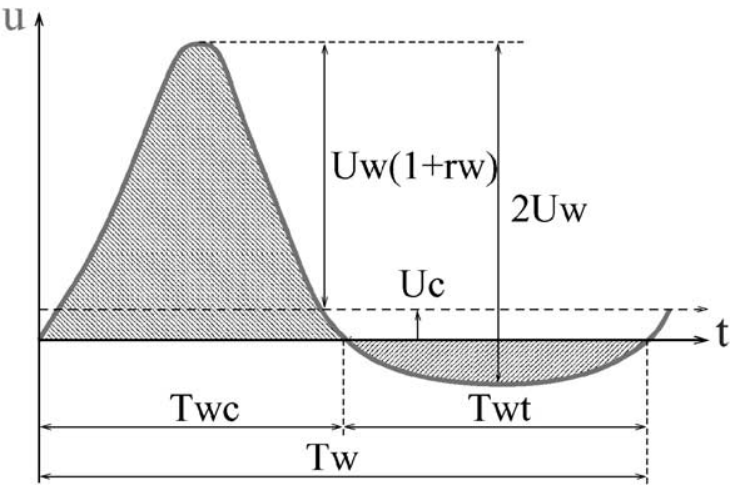

Fig. 1. Bottom velocity profile in the direction of the wave propagation (Dibajnia and Watanabe, 1992).

possible quantity of sand still in suspension after each half-cycle, and hence moving in the other direction (this phenomenon is also called "phase-lag" introduced by Dohmen-Janssen, 1999). This formula (as the Bailard and Ribberink formulae) enables transport under a non-linear wave to be described.

The solid volume flux is given by the following equation:

$\vec{q}_{\mathrm{s}}=A_{\mathrm{dw}} W_{\mathrm{s}} d \frac{\vec{\Gamma}}{\Gamma} \Gamma^{B_{\mathrm{dw}}}$

where $A_{\mathrm{dw}}=0.001$ and $B_{\mathrm{dw}}=0.55$ : coefficients of calibration, and with

$\vec{\Gamma}=\frac{T_{\mathrm{wc}} \overrightarrow{u_{\mathrm{wc}}}\left(\Omega_{\mathrm{c}}^{3}+\Omega_{\mathrm{t}}^{\prime 3}\right)+T_{\mathrm{wt}} \overrightarrow{u_{\mathrm{wt}}}\left(\Omega_{\mathrm{t}}^{3}+\Omega_{\mathrm{c}}^{\prime 3}\right)}{\left(u_{\mathrm{wc}}+u_{\mathrm{wt}}\right) T_{\mathrm{w}}}$

where $T_{\mathrm{w}}, T_{\mathrm{wc}}, T_{\mathrm{wt}}$ : period and half-periods of wave taking into account the effect of a current (cf. Fig. 1); $\Omega_{\mathrm{c}}, \Omega_{\mathrm{t}}$ : amount of sand entrained and settled during the half-period $T_{\mathrm{wc}}$ and $T_{\mathrm{w}}$, respectively; $\Omega_{\mathrm{c}}^{\prime}, \Omega_{\mathrm{t}}^{\prime}$ : amount of suspended sand remaining from the positive and the negative half-cycle, respectively; and $u_{\mathrm{wc}}, u_{\mathrm{wt}}$ : quadratic velocity (wave + current) over each half-period expressed as:

$u_{\mathrm{w} j}^{2}=\frac{2}{T_{\mathrm{w} j}} \int_{t}^{t+T_{\mathrm{w} j}} u^{2}(t) \mathrm{d} t+2 U_{\mathrm{c}}^{2} \sin ^{2} \theta$ 
where $j$ can be c or $\mathrm{t} ; u(t)=U_{\mathrm{c}} \cos \theta+u_{\mathrm{w}}(t), u_{\mathrm{w}}(t)$ : instantaneous wave orbital velocity; $\theta$ : angle between wave direction and current direction.

$$
\begin{aligned}
\text { if } \omega_{j} \leq \omega_{\mathrm{cr}} \quad \text { then } \Omega_{j} & =\omega_{j} \frac{2 W_{\mathrm{s}} T_{\mathrm{w} j}}{d} \\
& \text { and } \Omega_{j}^{\prime}=0, \\
\text { if } \omega_{j} \geq \omega_{\mathrm{cr}} \quad \text { then } \Omega_{j}=\frac{2 W_{\mathrm{s}} T_{\mathrm{w} j}}{d} & \\
\text { and } \Omega_{j}^{\prime} & =\left(\omega_{j}-1\right) \frac{2 W_{\mathrm{s}} T_{\mathrm{w} j}}{d},
\end{aligned}
$$

with:

$$
\omega_{j}=\frac{u_{\mathrm{w} j}^{2}}{2(s-1) g W_{\mathrm{s}} T_{\mathrm{w} j}}
$$

where $j$ can be cor t.

$\omega_{\mathrm{cr}}$ is a ripple parameter:

$$
\begin{aligned}
\omega_{\mathrm{cr}} & =0.03 & & \text { if } \Psi_{\mathrm{cw}(\max )} \leq 0.2 \\
& =1-0.97\left(1-\left(\frac{\Psi_{\mathrm{cw}(\max )}-0.2}{0.4}\right)^{2}\right)^{0.5} & & \text { if } 0.2<\Psi_{\mathrm{cw}(\max )}<0.6 \\
& =1 & & \text { if } 0.6<\Psi_{\mathrm{cw}(\max )}
\end{aligned}
$$

where $\Psi_{\mathrm{cw}(\max )}$ : maximum Shields parameter due the wave-current interaction (computed following method of Soulsby, 1997, pp. 87-95).

\subsection{Ribberink formula}

Ribberink proposed a quasi-steady model of bed load transport where the instantaneous solid flux is assumed to be proportional to a function of the difference between the actual time-dependent bed shear stress and the critical bed shear stress (see Fig. 2). This formulation has been calibrated towards several flume data sets including wave-current interaction in a plane regime (suspended load negligible) and field data (unidirectional flows in rivers).

The following expression for the sand transport rate was obtained:

$$
\begin{aligned}
\overrightarrow{q_{\mathrm{sb}}}= & m_{\mathrm{Rib}} \sqrt{(s-1) g d^{3}} \\
& \times\left\langle\left(|\overrightarrow{\Psi(t)}|-\Psi_{\mathrm{cr}}\right)^{n_{\mathrm{Rib}}} \frac{\overrightarrow{\Psi(t)}}{|\Psi(t)|}\right\rangle
\end{aligned}
$$

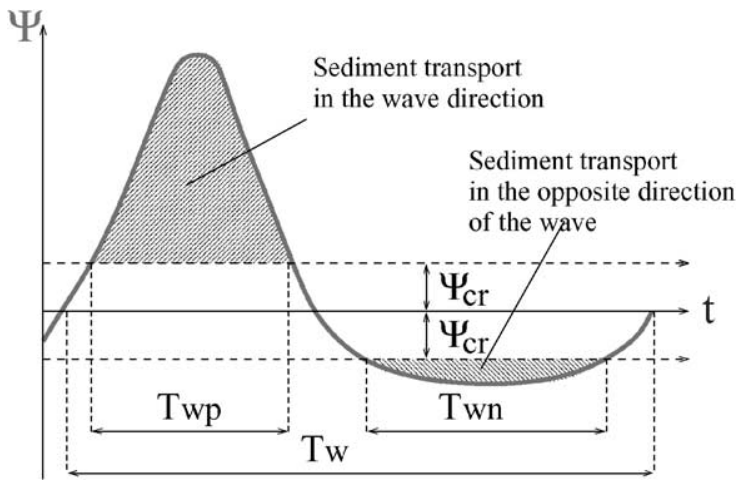

Fig. 2. Profile of the time-dependent shear stress (case where wave and current directions are the same).

where $\overrightarrow{\Psi(t)}=0.5 f_{\mathrm{cw}}|u(t)| \overrightarrow{u(t)} /[(s-1) g d]$ : timedependent Shields parameter (cf. Fig. 2) with the instantaneous velocity $\overrightarrow{u(t)}=\overrightarrow{U_{\mathrm{c}}}+\overrightarrow{u_{\mathrm{w}}(t)}$ and the wave-current friction factor $f_{\mathrm{cw}}$ computed according to the Madsen and Grant's (1976) method; $\Psi_{\text {cr: }}$ critical Shields parameter; \langle\rangle : time-averaged over several wave periods; and $m_{\mathrm{Rib}}=11, n_{\mathrm{Rib}}=1.65$ : adjusted coefficients.

In the same way as the Bailard formula, an equivalent wave-current friction coefficient has to be computed. Ribberink proposed to use the Madsen and Grant's (1976) method (see Section 3.1). He also proposed to compute total roughness values as follows:

$k_{\mathrm{st}}=\max \left(k_{\mathrm{s}} ; d\left[1+6\left(\langle|\Psi(t)|\rangle / \Psi_{\mathrm{cr}}-1\right)\right]\right)$

where $k_{\mathrm{s}}$ is skin roughness height.

\section{Important physical parameters for estimating sediment fluxes}

This section aims to demonstrate the importance of taking into account various parameters as roughness, phase-lag, and models of orbital bottom velocity profile of the waves when calculating sediment flux.

\subsection{Influence of roughness and friction coefficients}

The calculation of the total roughness value $k_{\mathrm{s}}$ seems to be a great challenge as it influences significantly the total sediment transport, although large 
uncertainties can be observed. The following models has been used to compute bed form characteristics and roughness, as well as sheet-flow roughness:

- current ripples: Soulsby's (1997) method (pp. 115 and 123),

- current megaripples: Van Rijn's (1993) method (pp. 5.14 and 6.8; Van Rijn 1993),

- wave ripples: Van Rijn's (1993) method (pp. 5.39 and 6.21),

- sheet- flow: Wikranmanayake and Madsen's (1991) method.

Figs. 3 and 4 show the marked influence of bed forms and sheet flow roughness values on the friction coefficient and hence on the estimation of shear stresses due to current or waves. A factor of 3 between skin and total shear stress due to the current can be observed and this factor becomes 5 for the shear stress due to waves. Many other formulae exist and often give very different results particularly for sheet flow conditions (cf. Dohmen-Janssen, p. 27). The Wikranmanayake and Madsen's method has been chosen as it produces the best results when compared to the available data for high sediment transport fluxes. Thus, it appears that significant errors in sediment transport computation can be induced through the calculation of total roughness. It is obvious that these roughness values are physical and significantly influence solid fluxes. Furthermore, some formulae have been calibrated taking into account bed forms and sheet flow roughnesses. Thus, we have attempted to take the influence of total roughness into account as far as possible with respect to the author's recommendations. In the absence of any recommendation, the presented models are used.

The roughness is included in sediment transport formulae via the friction coefficients due to current $f_{\mathrm{c}}$, or (and) due to waves $f_{\mathrm{w}}$. These coefficients are mainly increasing functions of grain size diameter (cf. Fig. 4 for skin roughness). But, if the total roughness is computed (method presented in the previous paragraph), the influence of hydrodynamic conditions prevails. The total friction coefficient $f_{\mathrm{ct}}$ is thus an increasing function with mean velocity $U_{\mathrm{c}}$ (cf. Fig. 4a). Because ripples appear more often for fine sediments, a small current has a bigger effect on the friction coefficient. On the other hand, the friction coefficient $f_{\mathrm{wt}}$ is very sensitive to small orbital velocities with coarser sediments. This effect decrease with an increasing $U_{\mathrm{w}}$ (cf. Fig. 4b). Otherwise, $f_{\mathrm{wt}}$ increase with $U_{\mathrm{w}}$. The total friction factor is thus very sensitive
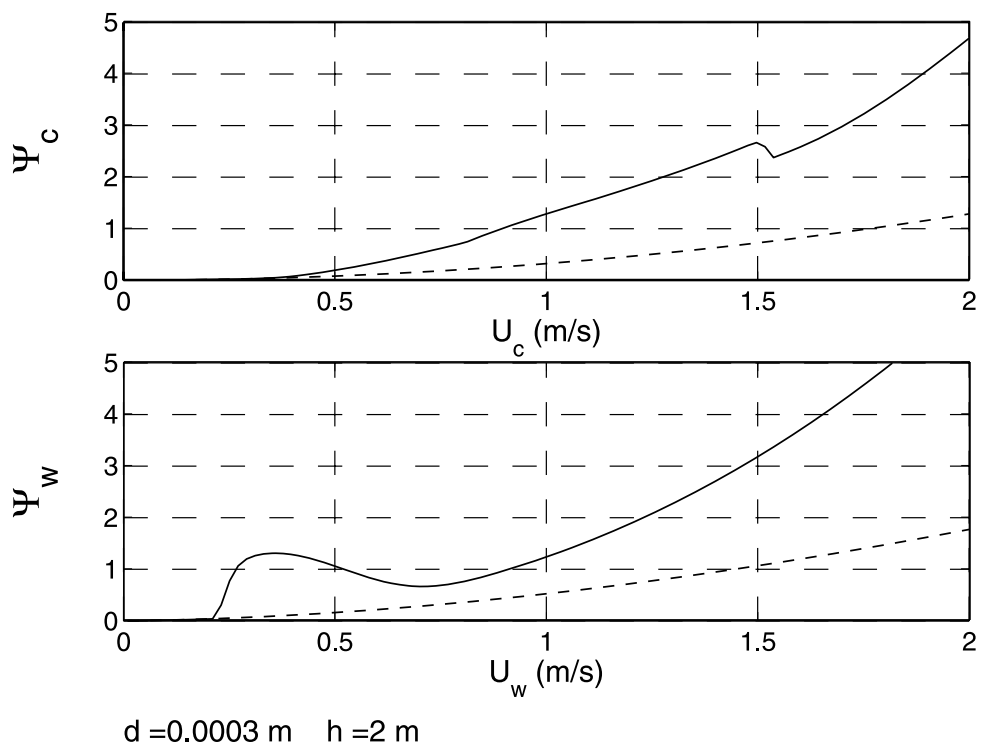

Fig. 3. Shields parameters $\Psi_{\mathrm{c}}$ and $\Psi_{\mathrm{w}}$ versus current and wave orbital velocity using skin roughness (dashed lines) or total roughness (solid lines). 
(a)

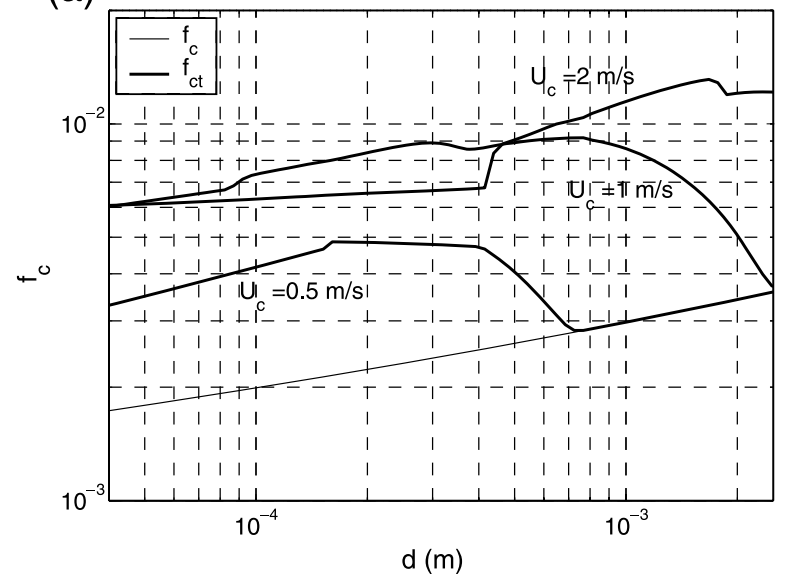

(b)

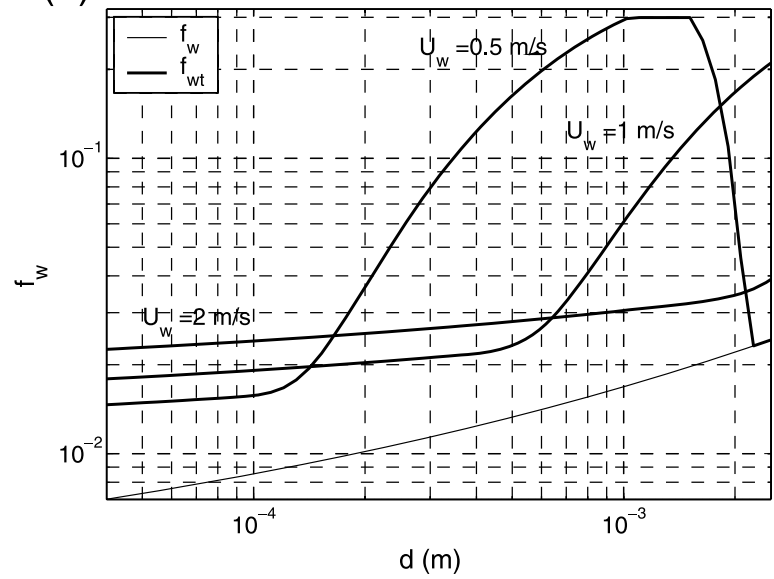

Fig. 4. Skin and total friction coefficients due to current $f_{\mathrm{c}}, f_{\mathrm{ct}}$ (a) and due to waves $f_{\mathrm{w}}, f_{\mathrm{wt}}$ (b) versus the mean grain size diameter for different hydrodynamic conditions $\left(U_{\mathrm{w}}=0 \mathrm{~m} / \mathrm{s}, h=2 \mathrm{~m}(\mathrm{a}) ; U_{\mathrm{c}}=0 \mathrm{~m} / \mathrm{s}, T_{\mathrm{w}}=6 \mathrm{~s}, h=2 \mathrm{~m}(\mathrm{~b})\right)$.

to grain size and current (or wave) velocity, and can often explain the sensitivity of formulae to these parameters.

At last, several formulations need a friction coefficient due to wave-current interaction. Indeed, friction coefficients due to current only or due to waves only do not have the same physical basis and display very different values $\left(f_{\mathrm{w}} / f_{\mathrm{c}} \approx 10-100\right)$. Madsen and Grant (1976) suggested a linear combination of the two friction coefficients:

$f_{\mathrm{cw}}=X f_{\mathrm{c}}+(1-X) f_{\mathrm{w}} \quad$ with $X=\frac{U_{\mathrm{c}}}{U_{\mathrm{c}}+U_{\mathrm{w}}}$

However, following the relation between friction coefficient and shear stress, $f_{\mathrm{cw}}$ can be computed from the maximum total shear stress over the bottom (computed using the Soulsby's (1997) method, pp. 87-95):

$f_{\mathrm{cw}}=\frac{\tau_{\mathrm{cw}, \max }}{0.5 \rho\left\langle|\vec{u}|^{2}\right\rangle}$

On Fig. 5, it can be seen that results obtained from these two different methods remain more or less similar. However, when waves prevail, Eq. (21) predict values for $f_{\text {cw }} 20 \%$ bigger than Eq. (20) and even bigger than $f_{\mathrm{w}}$. Afterwards, in this paper, the Madsen and Grant's method will be used.

\subsection{Influence of phase-lag}

As most of the sediment transport occurs near the bed in the sheet flow case, it is often assumed that the response time of the sediment is a lot shorter than the wave period. Sediment transport in oscillating fluxes is generally considered as quasi-steady, implying that the instantaneous sand flux is a function of a certain power of the instantaneous velocity. However, Ribberink and Chen (1993), during their experiment in an oscillating flume, observed that for fine sand $(d=0.13 \mathrm{~mm})$ and second-order Stokes waves, the sediment flux is much lower than expected, and can even be in the opposite direction to the steady current. This contradicts the quasisteady hypothesis.

An explanation of this phenomenon may be the phase-lag of the sand's response to the fluid. The quantity of sediment in suspension depends essentially on the instantaneous velocity, but it also depends on the settling velocity. In the case of oscillating flows, not all the sand grains put into suspension during the first half-period settle during this same half-period. The proportion still in suspension is then carried away in the opposite direction during the second half-period. 
(a)

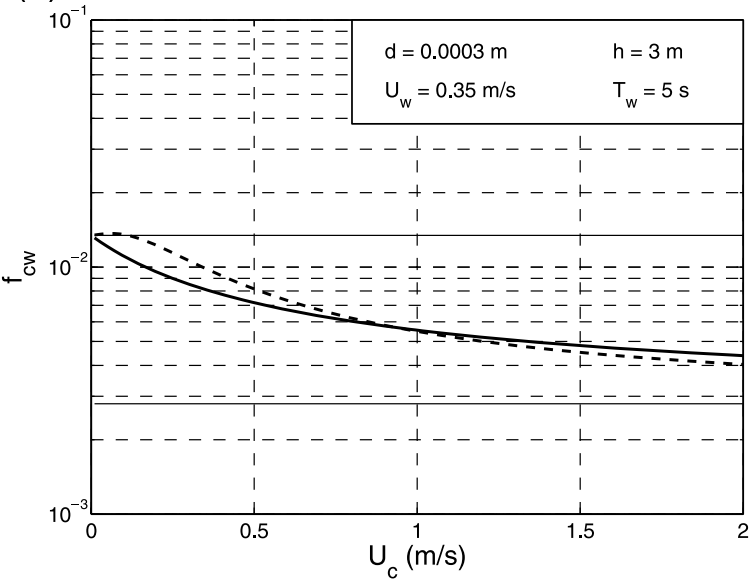

(b)

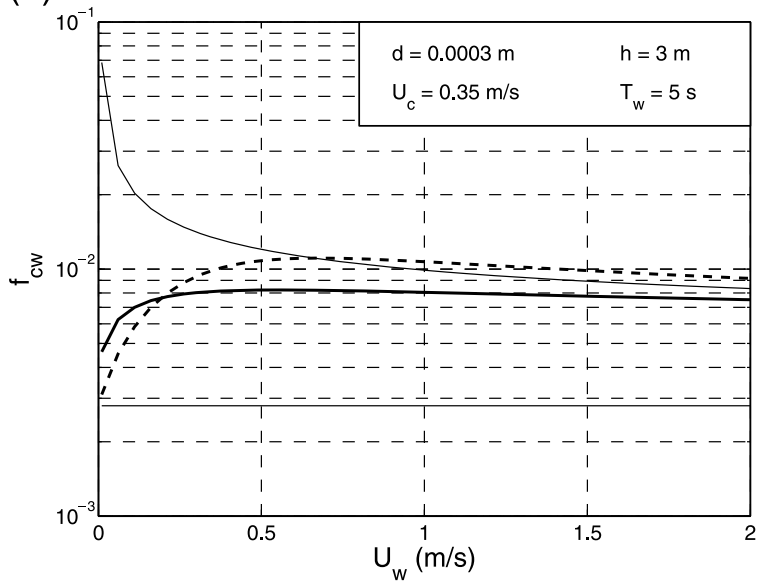

Fig. 5. Skin friction coefficient for wave and current interaction $f_{\text {cw }}$ computed following Eq. (20) (solid lines) or Eq. (21) (dashed lines) versus mean current (a) or wave orbital velocity (b); fine solid lines correspond to skin friction coefficients $f_{\mathrm{c}}$ and $f_{\mathrm{w}}$.

Dohmen-Janssen (1999) introduced the parameter $p$ to express the importance of phase-lag:

$p=\frac{t_{\mathrm{settling}}}{T_{\mathrm{w}}}=\frac{\delta}{W_{\mathrm{s}} T_{\mathrm{w}}}$

where $\delta$ : height at which the particle is situated and $W_{\mathrm{s}}$ : settling velocity.

Dohmen-Janssen proposed to use Wilson's (1987) formulation for the thickness of the sheet flow layer, thus: $\delta=10 \Psi_{\mathrm{w}} d$.

In case of rippled beds, phase-lags can also occur quite often (suspension due to the bed forms, reversal flow on the lee side of the ripple caused by eddies) and thus have a large influence on the transport rate. However, as rippled beds often correspond to relatively small shear stresses and, consequently, to small sediment transport rates, this specific case will not be studied in this paper.

\subsection{Influence of second-order wave velocity profiles}

In morphodynamic models, it is often necessary to describe waves as simply as possible, simultaneously being as consistent with reality as possible. Bottom velocity profiles often become non-linear near the coast, which results in positive net transport shoreward. However, waves are often considered to be sinusoidal in morphodynamic models and thus are only a function of two parameters: the magnitude of the bottom orbital velocity $U_{\mathrm{w}}$ and the period $T_{\mathrm{w}}$, yielding an instantaneous velocity:

$u_{\mathrm{w}}(t)=U_{\mathrm{w}} \sin \left(\frac{2 \pi t}{T_{\mathrm{w}}}\right)$

Nevertheless, introducing a third parameter would enable the velocity profile to be simulated more correctly. The asymmetry coefficient $R_{\mathrm{w}}$ is defined as the quotient between the maximum positive velocity of the wave and its amplitude $\left(R_{\mathrm{w}}=u_{\mathrm{w}(\max )} /\left(u_{\mathrm{w}(\max )}-\right.\right.$ $\left.\left.u_{\mathrm{w}(\min )}\right)=u_{\mathrm{w}(\max )} /\left(2 U_{\mathrm{w}}\right)\right)$. The asymmetry can also be written with the coefficient $r_{\mathrm{w}}=2 R_{\mathrm{w}}-1$. The wave velocity equation becomes:

$u_{\mathrm{w}}(t)=U_{\mathrm{w}}\left[\sin \left(\frac{2 \pi t}{T_{\mathrm{w}}}\right)+r_{\mathrm{w}} \sin \left(\frac{4 \pi t}{T_{\mathrm{w}}}\right)\right]$

Fig. 6 shows the relevance of using the term $r_{\mathrm{w}}$ for the velocity asymmetry. The velocity profile obtained with the second order is much closer to some experimental results. (The experimental profile given by Dibajnia and Watanabe, 1992 corresponds to the first order of the cnoidal theory which is a quite good representation of a non-breaking wave.) Thus, assuming the sand flux to be proportional to the instantaneous velocity to the power three, the resultant error is much lower using the second-order theory. 


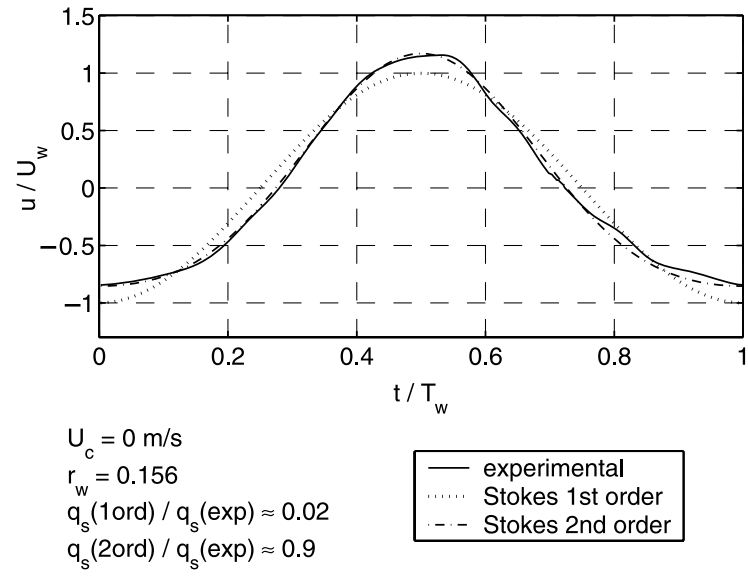

Fig. 6. Velocity profiles and sediment transport obtained from different wave models (the experimental profiles are from the experiments of Dibajnia and Watanabe, 1992).

Among the formulae studied, only those of Bailard, Dibajnia and Watanabe, and Ribberink enable second order velocity profiles to be used. As a consequence, computations of the terms $\left\langle|\vec{u}|^{2} \vec{u}\right\rangle$ and $\left\langle|\vec{u}|^{3} \vec{u}\right\rangle$ in the Bailard formula, the quadratic velocities in the Dibajnia and Watanabe formula and the average of the time-dependent shear stress in the Ribberink formula are more correctly represented using the second order of the Stokes waves. The main differences can be observed for cases without current, where only those formulae taking into account the second order produce a net transport. Better results are also obtained for the cases where the current velocity is slightly lower than the wave orbital velocity $\left(\left(1-r_{\mathrm{w}}\right) U_{\mathrm{w}}<U_{\mathrm{c}}<U_{\mathrm{w}}\right)$, as the half-period $T_{\mathrm{wc}}$ and the velocity peaks are better estimated (the "flat" shape of the negative part of the velocity profile is more realistically described). To improve this effect, the cnoidal theory must be used but no analytical computation is then allowed for the velocity moments.

\section{Comparison between studied formulae and field and experimental data}

\subsection{General points and data presentation}

According most of the authors, their formulae give results that are very close to their own experimental data. However, it is almost impossible to find a simple formula that is valid for every applicable case, as so many parameters exist and interact together. Some formulations may simply be more suited for one case or another. A comparison with a large quantity of data is very interesting in order to observe whether a formula gives correct results for the main cases; but such a comparison must be supplemented with a study of how the formulae behave with respect to the key parameters of sediment transport over a wide range of parameter values.

Major morphological changes occur during high hydrodynamic stresses. It is therefore essential that sediment transport formulae should give accurate results for strong currents and/or high waves. To check this, the five formulae studied are compared to experimental data mainly corresponding to the sheet flow regime. Comparisons were made for cases with strong currents without waves (according to Voogt et al., 1991 with the headings Krammer and Scheldt corresponding to the names of the beaches), and laboratory data in an oscillating flume (according to Al Salem, 1993; Ribberink and Al Salem, 1994 with the heading Alsalem; Dohmen-Janssen, 1999 with the heading Janssen; Dibajnia and Watanabe, 1992; Dibajnia, 1995 with the heading Dibajnia).

It is often considered that the estimation of sediment flux is acceptable when it is between 0.5 and 2 times the experimental data. Therefore, in the following graphs, the curves $q_{\mathrm{s}(\text { num })}=q_{\mathrm{s} \text { (data) }}$ (solid line) and $q_{\mathrm{s} \text { (num) }}=0.5$ or $2 q_{\mathrm{s} \text { (data) }}$ (dashed lines) are given. For each comparison with the data, the percentage of points with less than $50 \%$ error and less than $20 \%$ error is also computed for "current only" data and "wave-current" data (i.e., Cc50, Cc80, Cw50, and $\mathrm{Cw} 80$, respectively). In case of negative data (current direction opposite to wave direction), the absolute value is presented on the graph only if the formula predict the correctly induced direction of the sediment transport. If the direction of transport is predicted incorrectly, an error up to $100 \%$ is considered.

\subsection{Bijker formula}

Fig. 7 shows that the Bijker formula tends to underestimate solid transport mainly for wave-current interaction where the errors may reach several orders of magnitude. This can be explained by the fact that the Bijker formula takes into account waves only 


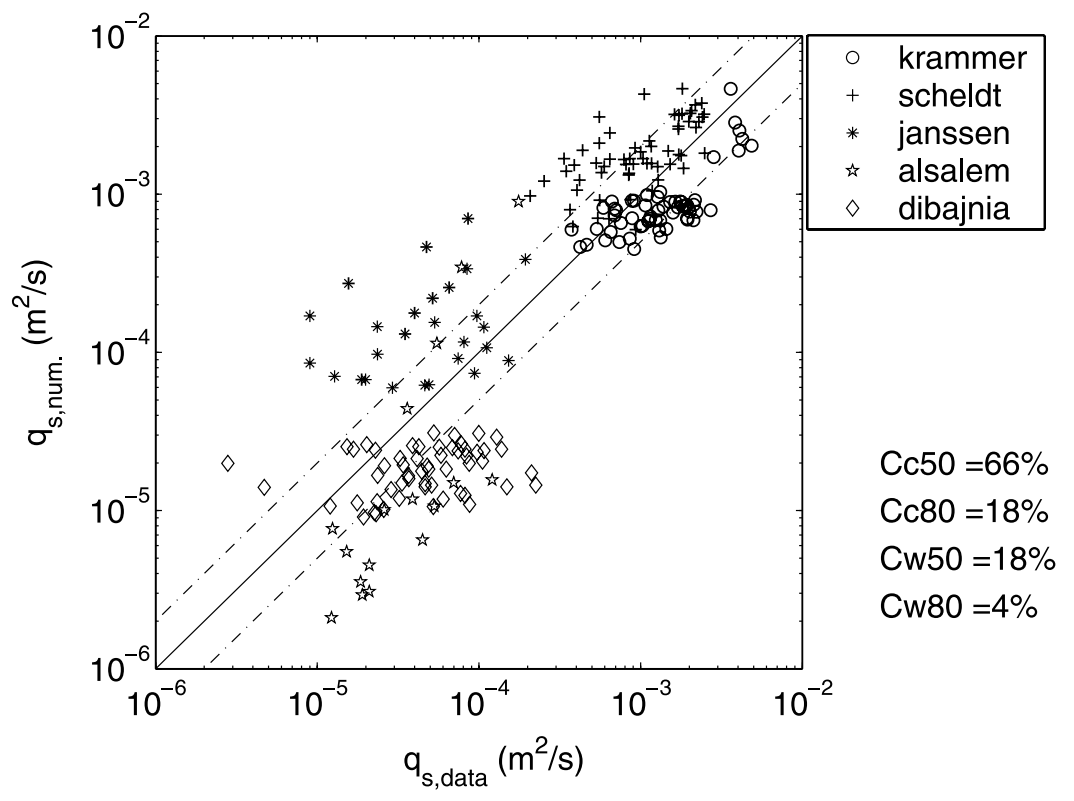

Fig. 7. Comparison between the Bijker formula and experimental data (explanation of legend in Section 4.1).

as an active term for suspension. Thus, even when the wave orbital velocity is high (and also the asymmetry), if the steady current is very low, the net sediment transport will also be very low. The results for cases with purely waves are therefore very scattered. In cases without waves, the results are better (Cc50 up to $65 \%$ ), but still less good than for the other formulae and very sensitive to the computation of the total roughness. Using skin friction results in serious underestimation, particularly for the coarsest sediments.

\subsection{Bailard formula}

Using the present experimental data, it is possible to compare different methods for estimating the friction coefficient $f_{\mathrm{cw}}$ derived from Bailard formula (cf. Section 3.1). With the Madsen and Grant's method or by extracting this coefficient from the total shear stress $\tau_{\mathrm{cw}}$, similar results are obtained but a clear overestimation has been observed in the case of a wave-current interaction. In Fig. 8, good agreement with the experimental data can be observed (much better than with the Bijker formula) using the Madsen and Grant's method with the skin friction due to waves. However, slight scatter can be observed for wave-current interaction cases (over-estimation for the Janssen data and underestimation for the Dibajnia data). Finally, it may be stated that, using the Stokes second-order theory for waves in the case of asymmetric waves with a weak current (case of the Alsalem data), a clear improvement in the results is observed.

\subsection{Van Rijn formula}

One advantage of the Van Rijn formula is that it takes into account many physical parameters to estimate bed load and suspended load. Thus, for instance, only skin friction is considered for bed load, while total friction is considered for suspended load; effects of turbulence are included and the velocity profile over the depth is computed. On the other hand, many parameters, that are not always easy to estimate, significantly complicate the computations. Suspension is highly sensitive to parameters such as reference concentration or mixing coefficient, which involve considerable uncertainties. Moreover, computing suspended load while resolving the integrals is timeconsuming.

The Van Rijn formula yields reasonable results (Cc50 up to $70 \%$ and $\mathrm{Cw} 50$ up to $45 \%$ ), with only a slight underestimation in the case of wave-current interactions (cases from the Dibajnia data) and an 


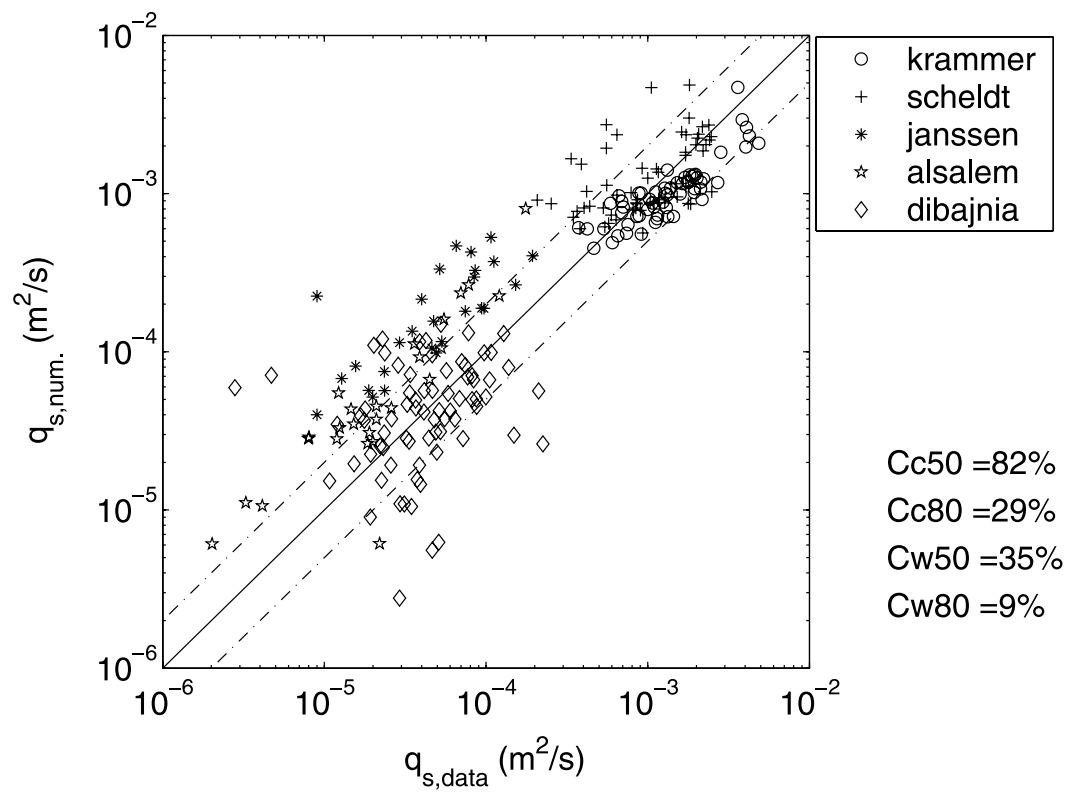

Fig. 8. Comparison between the Bailard formula and experimental data (explanation of legend in Section 4.1).

overestimation for some cases (very fine sediments) of the Scheldt data (cf. Fig. 9). But, in the same way as the Bijker formula, considerable errors appear for cases with asymmetric waves opposite to current.

\subsection{Dibajnia and Watanabe formula}

The Dibajnia and Watanabe formula gives good results for most of the cases studied (the best results for the five studied formulae, Cc50 $=84 \%$ and $\mathrm{Cw} 50=$

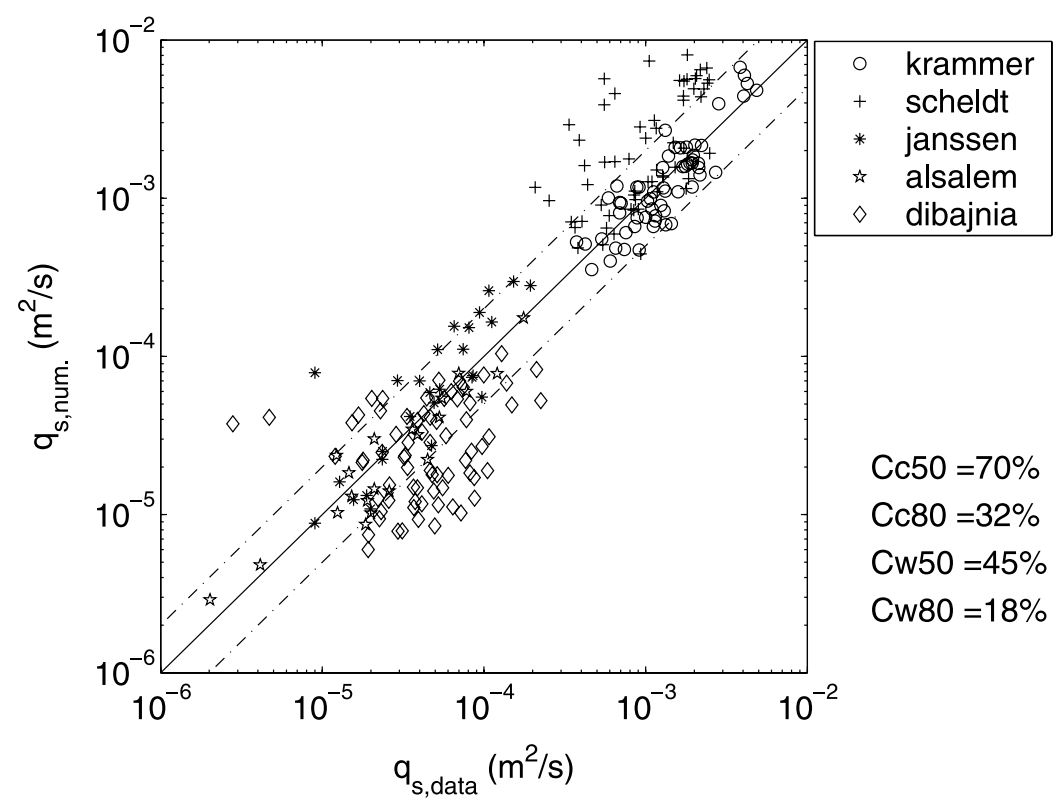

Fig. 9. Comparison between the Van Rijn formula and experimental data (explanation of legend in Section 4.1). 


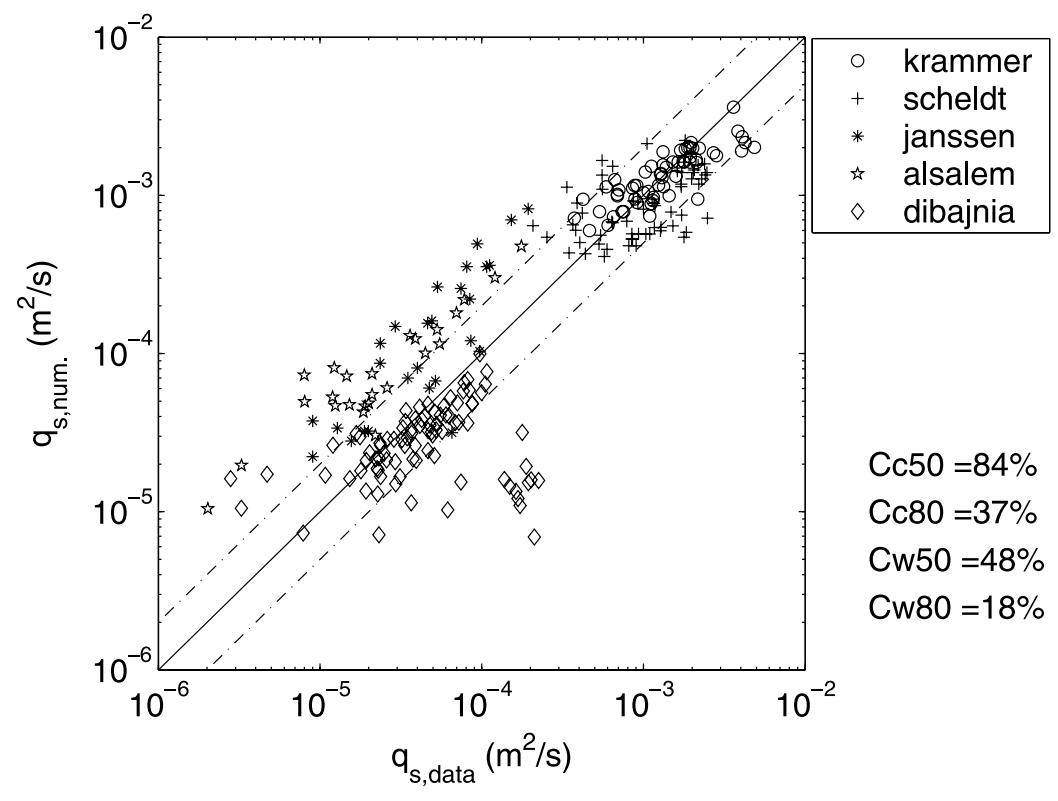

Fig. 10. Comparison between the Dibajnia and Watanabe formula and experimental data (explanation of the legend in Section 4.1).

46\%). However, a slight underestimation can be observed in Fig. 10 for the Scheldt and Krammer data, and a slight overestimation for the Janssen and Alsalem data. Nevertheless, the results remain less scattered than with some of the previous formulae.

\subsection{Ribberink formula}

Finally, the Ribberink formula gives good results in case of wave-current interaction, but significantly underestimates the sediment transport for the cases

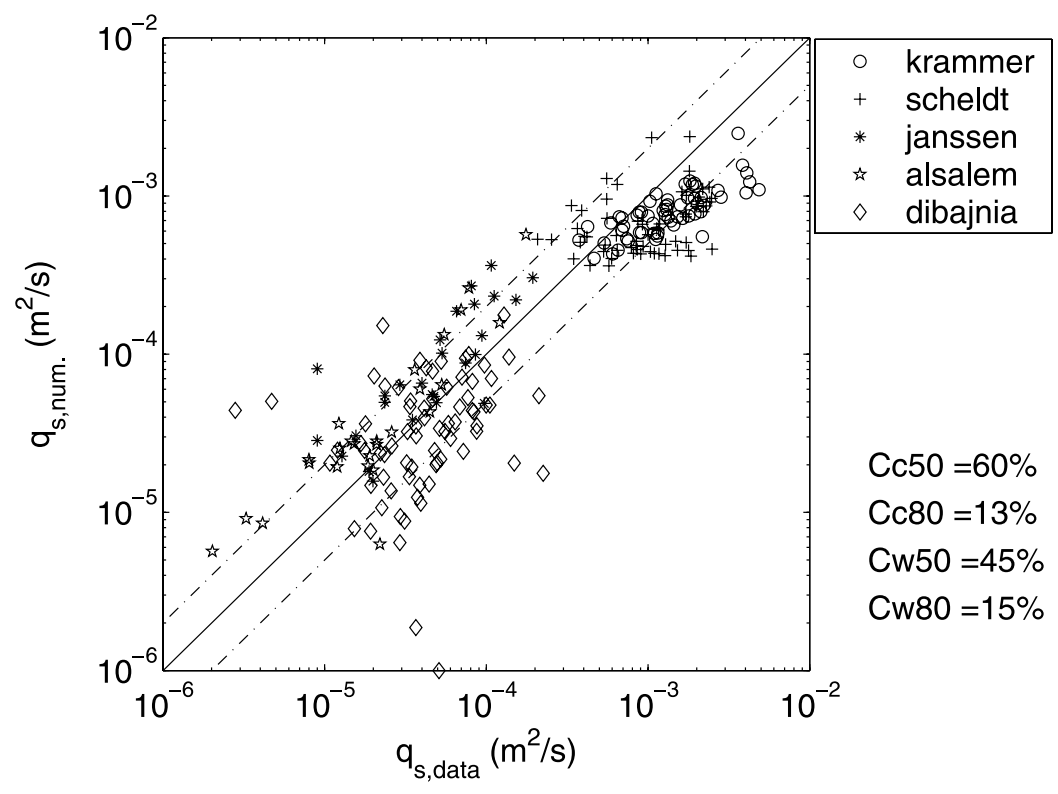

Fig. 11. Comparison between the Ribberink formula and experimental data (explanation of the legend in Section 4.1). 
with strong currents, and thus with high suspended load (see experimental results from the Scheld and Krammer beaches; Fig. 11). It can easily be explained by the fact that this formula was only adjusted for cases with bed load and sheet flow (without suspension).

As for the Bailard formula, a difficulty which occurs is the estimation of the wave-current friction coefficient. The best results were obtained using the Madsen and Grant's method but using the total shear stress due to current (computed as presented in paragraph 3.1, bed form effects included).

\section{Behaviour of sediment transport formulae}

To validate each of these formulae more completely, it is interesting to study their behaviour with respect to the main parameters of sediment transport. Indeed, while all these formulae give nearly equivalent results for a large amount of data (cf. Section 4), their behaviour in relation to a single parameter can differ a lot. These formulae are often calibrated with a fairly narrow range of values of these parameters and, outside this range of values, the sediment flux may be wrongly estimated.

Unfortunately, obtaining a suitable amount of experimental data (i.e., data where only one parameter varies) for this study is quite difficult, particularly in the case of field studies. Thus, the lack of data prevents any firm conclusion being reached with regard to differences in sediment transport behaviour.

\subsection{Grain size influence}

Grain size diameter $d$ appears in the formulae mainly through the friction coefficients $f_{\mathrm{c}}$ and $f_{\mathrm{w}}$ and the settling velocity $W_{\mathrm{s}}$. These three parameters are all increasing functions of the grain size. Thus, as grain size diameter increases, suspended load decreases because of the increased settling velocity, but shear stresses increase as the friction coefficients increase. However, Shields parameter is a decreasing function of grain size. A critical grain size diameter must therefore exist for a given hydrodynamic field, where the critical Shields parameter is reached, and thus where the sediment flux is equal to zero.

The curves in Fig. 12 show the behaviour of the sediment transport rate in relation to grain size diam- eter. While the results are relatively close to each other for the classical cases studied (i.e., $10^{-4}<d<3 \times 10^{-4}$ $\mathrm{m})$, they diverge rapidly beyond this range of values.

Thus, for fine sediments $(d \leq 0.1 \mathrm{~mm})$, while the Dibajnia and Watanabe formula gives increasing sediment transport with grain size, Bijker, Bailard, and Van Rijn formulae display the opposite behaviour. In the case of waves prevailing (cf. Fig. 12a), the experimental values obtained by Dohmen-Janssen seem to indicate that the Dibajnia and Watanabe formula shows the best behaviour. This confirms the importance of phase-lag effects for this particular case. The Bijker and Bailard formulae, which are very sensitive regarding fine sediments, may largely overestimate sediment flux for such cases.

On the other hand, when the steady current is significant (cf. Fig. 12b), or predominant (cf. Fig. 12c), fine sediments that are easily put in suspension move with the current. Then, the Bijker, Bailard, and Van Rijn formulae display a correct behaviour. Unfortunately, the lack of data for fine sediment prevents any quantitative conclusion from being reached, either for the negative values given by the Dibajnia and Watanabe formula (prevailing waves) or for the high sediment transport predicted by the Bijker, Bailard, and Van Rijn formulae (prevailing current). A reason for this lack of data is that the limit of the sediments below which they become cohesive is about $d=0.06 \mathrm{~mm}$. The investigated formulae suppose non-cohesive sediment.

In the case of a larger grain size $(>1 \mathrm{~mm})$, two parameters influence the sediment transport. First, if bed load transport prevails, the sediment transport must be an increasing function of the mean grain size diameter due to the friction coefficient (cf. paragraph 3.1 and Fig. 4). On the other hand, the Shields parameter decreases rapidly with an increasing grain size to reach its critical value, which means that there is no longer any sediment flux. Apart from the Van Rijn formula, which takes into account this critical value, all the formulae predict sediment transport that is nearly independent of grain size. Experimental data on Fig. $12 b$ and $c$ indicate this behaviour. But for these two cases, the critical grain size is up to $d=0.01$ $\mathrm{m}$, which is larger that the experimental values. It must however be stated that the Bijker formula is extremely sensitive to roughness: for $d>1 \mathrm{~mm}$, using skin friction, this formula estimate a sediment flux 
(a)

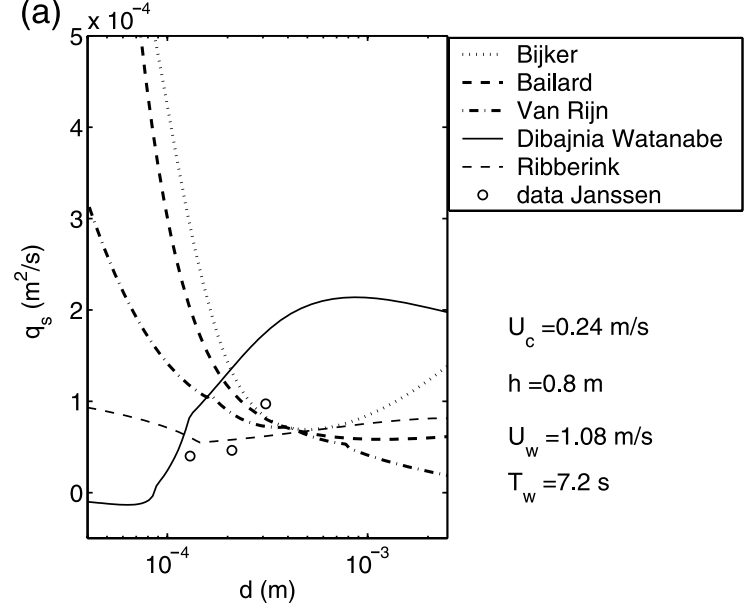

(b)

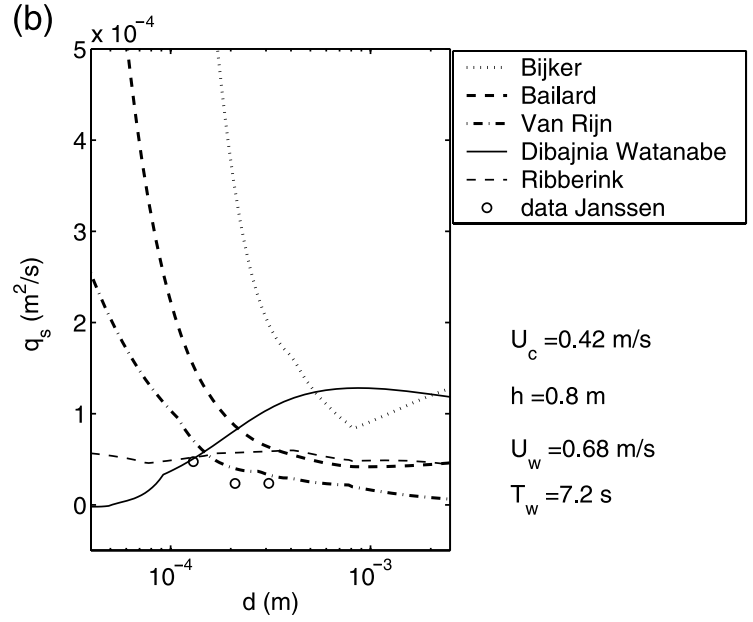

(c)

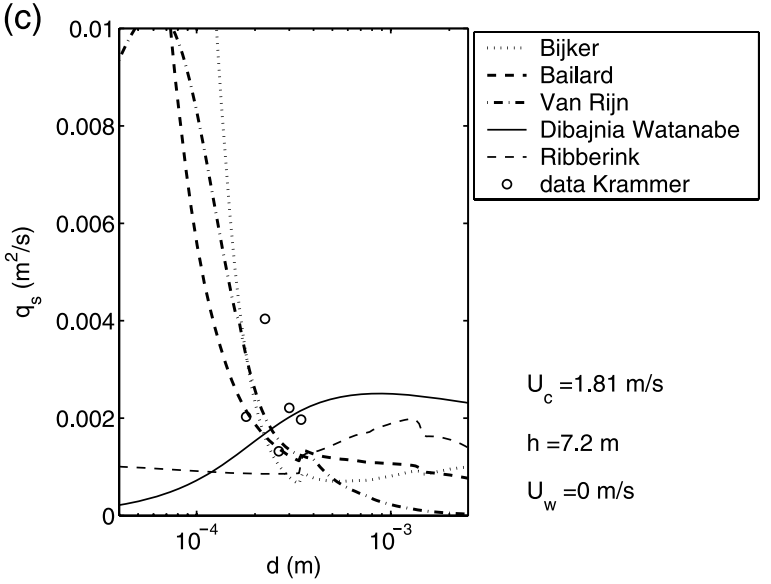

Fig. 12. Influence of grain size diameter on sediment transport for a case where waves prevail (a), a case with waves and current (b) and a case with current only (c).

very close to zero, whereas using the total friction it gives a sediment flux that increases substantially with the diameter, which seems to be unrealistic for grain size up to $2 \mathrm{~mm}$.

The Ribberink formula shows an unrealistic behaviour in relation to grain size diameter whatever the case. Thus, this formula is nearly independent of the grain size. This can be explained by the term $\sqrt{(s-1) g d^{3}}$ proposed by Ribberink as a reference sediment flux, which could be too sensitive to sand diameter and then inhibit the influence of the grain size in the computation of the shear stress. The Ribberink formula was calibrated for transport on a plane bed, where suspended load is negligible. In case of high suspension (cf. Fig. 12c), the underestimation is thus logical.

\subsection{Influence of wave orbital velocity}

Waves were originally believed to affect sediment transport mainly by increasing the suspension as a result of oscillating flow (cf. Bijker, 1968). Thus, the higher the orbital velocity, the higher the sediment flux. This is verified in Fig. 13b, where, for a grain size of $0.2 \mathrm{~mm}$ and a significant current, sediment transport is an increasing function of wave orbital velocity. The five formulae studied have a consistent behaviour in relation to the experimental 
(a)

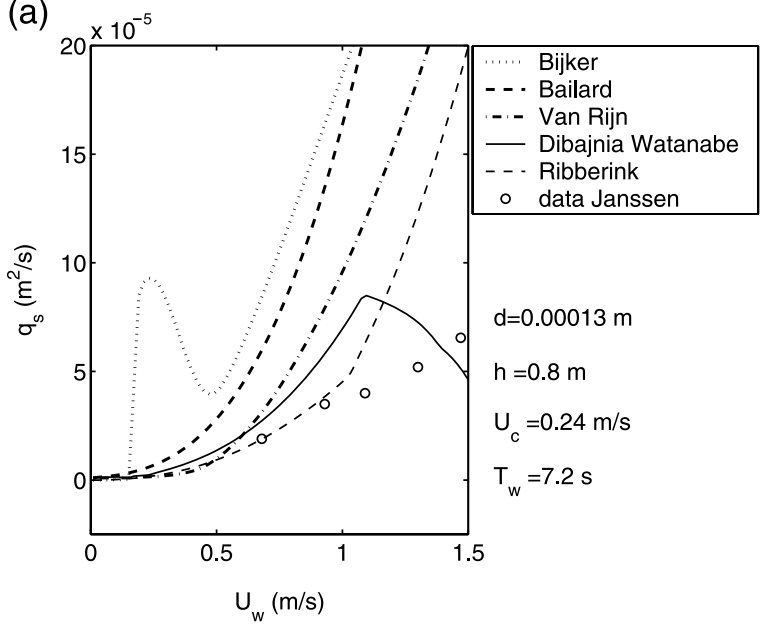

(b)

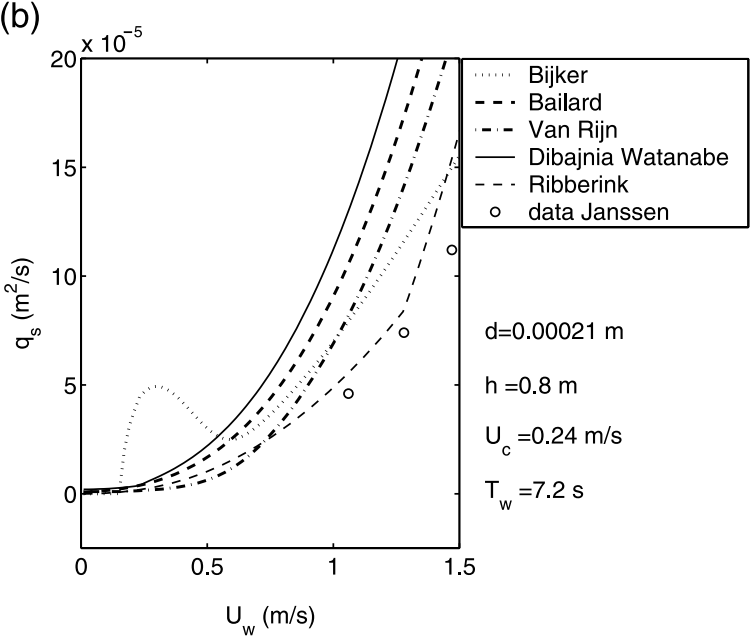

Fig. 13. Influence of wave orbital velocity on sediment transport for a case with weak current and fine sands $(0.13 \mathrm{~mm})(\mathrm{a})$ and a case with stronger current and sand diameter of $0.21 \mathrm{~mm}(\mathrm{~b})$.

data of Dohmen-Janssen. But only the Ribberink formula give relatively reasonable results for the amplitude of the transport in this case. The four other formulae overestimate the sediment rate maybe because they include suspended load, whereas no suspended load was observed in the oscillating flume.

In the case of fine sediments with a small current (cf. Fig. 13a), the phase-lag phenomenon can be observed easily. The experimental data of DohmenJanssen indicate for $U_{\mathrm{c}}=0.24 \mathrm{~m} / \mathrm{s}$ and $d=0.13 \mathrm{~mm}$ a sediment flux lower than the case with $d=0.21$ $\mathrm{mm}$ when wave orbital velocity rises beyond 1.1 $\mathrm{m} / \mathrm{s}$ (smaller slope of increase with the wave orbital velocity). Thus, explaining this phenomenon with the suspension phase-lag in relation to instantaneous velocity appears to be clearly justified. Only the Dibajnia and Watanabe formula is in agreement with the data, although it tends to exaggerate the phaselag effects (which only stand out as a curb of the sediment flux). The Bijker, Bailard, Van Rijn, and Ribberink formulae do not take into account phaselag, and largely overestimate sand fluxes in this case.

\subsection{Wave period influence}

Wave period is included in the formulae mainly via the friction coefficient due to waves, which is a decreasing function of the wave period. This explains the sensitivity to wave period of the Bijker, Bailard, Van Rijn, and Ribberink formulae. In the case of the Van Rijn formula, wave period is also involved in the computation of the boundary layer thickness $\delta_{\mathrm{w}}$ (an increasing function of $T_{\mathrm{w}}$ ), which has an important effect on the estimation of suspended load (a decreasing function of $\delta_{\mathrm{w}}$ ). This may explain the high increase estimated by the Van Rijn formula for decreasing wave period (cf. Fig. 14). For a case where waves do not prevail, a decreasing period leads to a decreasing bottom excursion $A_{\mathrm{w}}$, and thus a decrease of the suspension. The Ribberink formula include wave period only via the friction coefficient $f_{\mathrm{w}}$, but to the power $n_{\mathrm{Rib}}$, which explains the high decrease.

Dohmen-Janssen's data indicate an important increase in the sediment flux with wave period. This behaviour is accentuated in the case of waves prevailing. With the idea of phase-lag, this can be easily explained: the shorter the wave period, the more sediment stays in suspension after the first half-period. Thus, sediment transport is attenuated in the direction of the waves. The experimental data confirm that only the Dibajnia and Watanabe formula behaves correctly in relation to this parameter. Fig. 14b shows how much a larger sediment inhibits the phase-lag effects. This confirms the correct behaviour of the Dibajnia and Watanabe formula. 

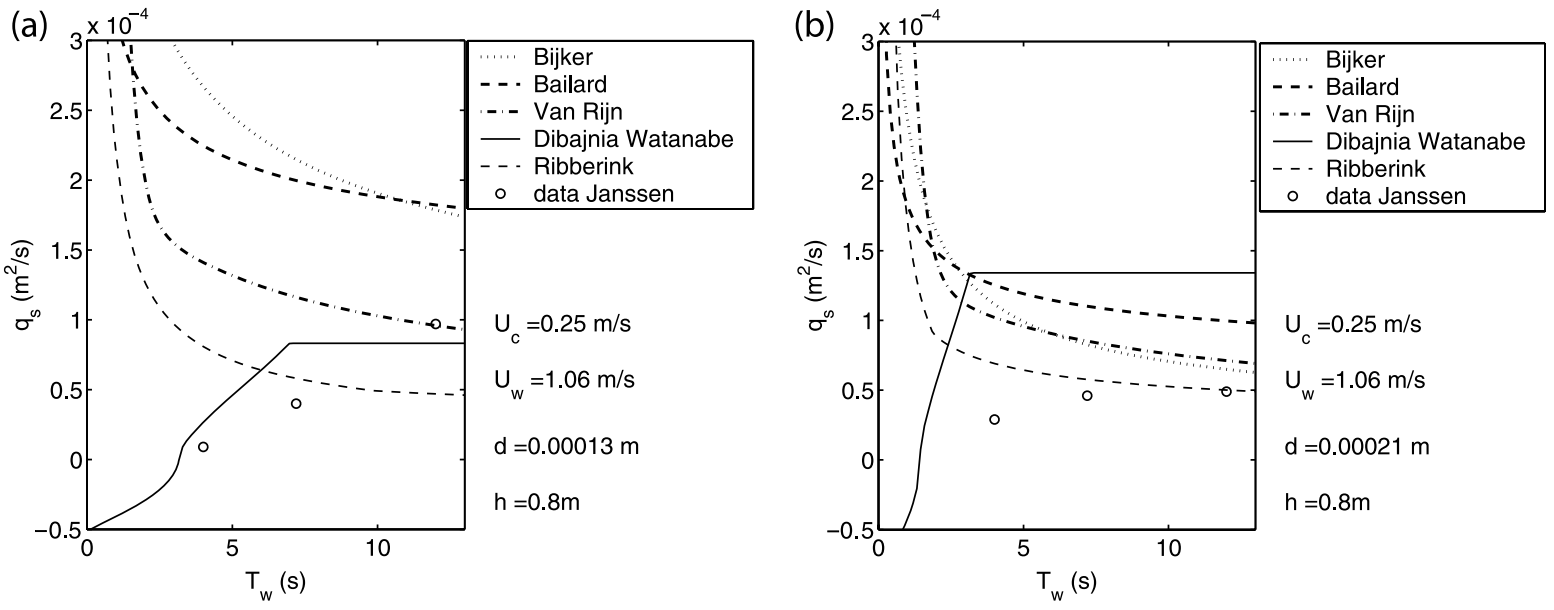

Fig. 14. Influence of wave period on sediment transport in case of very fine (a) and fine (b) sand.

To parameterize the phase-lag effect, DohmenJanssen (1999) introduced a phase-lag correction factor:

$r_{\mathrm{pl}}=\frac{\left\langle q_{\mathrm{s}, \mathrm{r}}(t)\right\rangle}{\left\langle q_{\mathrm{s}, \mathrm{eq}}(t)\right\rangle}$

where $q_{\mathrm{s}, \text { eq }}(t)$ is the "equilibrium" transport rate (without phase-lag effects) and $q_{\mathrm{s}, \mathrm{r}}(t)$ is the "real" transport rate (with phase-lag effects).

To estimate this factor $r_{\mathrm{pl}}$, Dohmen-Janssen developed an analytical diffusion model for sediment concentrations. From the studies of influence of wave orbital velocity and period, assuming that the timeaveraged "equilibrium" sediment rate $\left\langle q_{\mathrm{s} \text {,eq }}(t)\right\rangle$ is independent of wave period and, with respect to the proportionality with the velocity moment to the power three (cf. Al Salem, 1993), it is also possible to estimate the factor $r_{\mathrm{pl}}$, using experimental data and results from the Dibajnia and Watanabe formula. Results are shown in Fig. 15. Case 1 corresponds to Fig. 13a, where the relation $\left\langle q_{\mathrm{s}, \mathrm{r}}(t)\right\rangle=\left\langle q_{\mathrm{s}, \mathrm{eq}}(t)\right\rangle$ is supposed to be reached for $U_{\mathrm{w}}=0.68$. Case 3 corresponds to Fig. 14a and case 4 to Fig. 14b, where the relation $\left\langle q_{\mathrm{s}, \mathrm{r}}(t)\right\rangle=\left\langle q_{\mathrm{s}, \mathrm{eq}}(t)\right\rangle$ is supposed to be reached for $T_{\mathrm{w}}=\infty$. Case 2 is identical to case 3 except for the orbital velocity, which is weaker $\left(U_{\mathrm{w}}=0.68 \mathrm{~m} / \mathrm{s}\right.$ instead of $1.06 \mathrm{~m} / \mathrm{s}$ ).

Firstly, it can be observed that the factor $r_{\mathrm{pl}}$ seems to be linearly related to the phase-lag parameter $p$ after a minimum value has been exceeded $\left(p_{\min } \approx 0.05\right)$, but it seems to be also function of the hydrodynamic parameters. While the model of Dohmen-Janssen predicts a too small factor $r_{\mathrm{pl}}$ (and nearly independent of the different cases studied as $0.16<U_{\mathrm{c}} / U_{\mathrm{w}}<0.37$ ), the Dibajnia and Watanabe formula predicts the appearance of the phase-lag effects for larger values of $p$ and seems to be too sensitive to larger values of $p$. The greater value of $p_{\min }$ obtained from case 1 could be only due to the fact that $\left\langle q_{\mathrm{s}, \mathrm{r}}(t)\right\rangle$ is lower than $\left\langle q_{\mathrm{s}, \text { eq }}(t)\right\rangle$ for $U_{\mathrm{w}}=0.68$. An empirical relation for $r_{\mathrm{pl}}$ is thus proposed:

$$
\begin{array}{ll}
r_{\mathrm{pl}}=1-0.2(p-0.05) & \text { if } p>0.05 \\
r_{\mathrm{pl}}=1 & \text { if } p \leq 0.05
\end{array}
$$

At last, it could be interesting to compare these results with phase-lag effects on a rippled bed. But, to the authors' knowledge, no data are available to study this case.

\subsection{Influence of wave asymmetry}

In Section 3.3, it was shown that wave asymmetry considerably influences sediment transport. Fig. 16 clearly shows that sediment flux is an increasing function of wave asymmetry. Among the formula- 

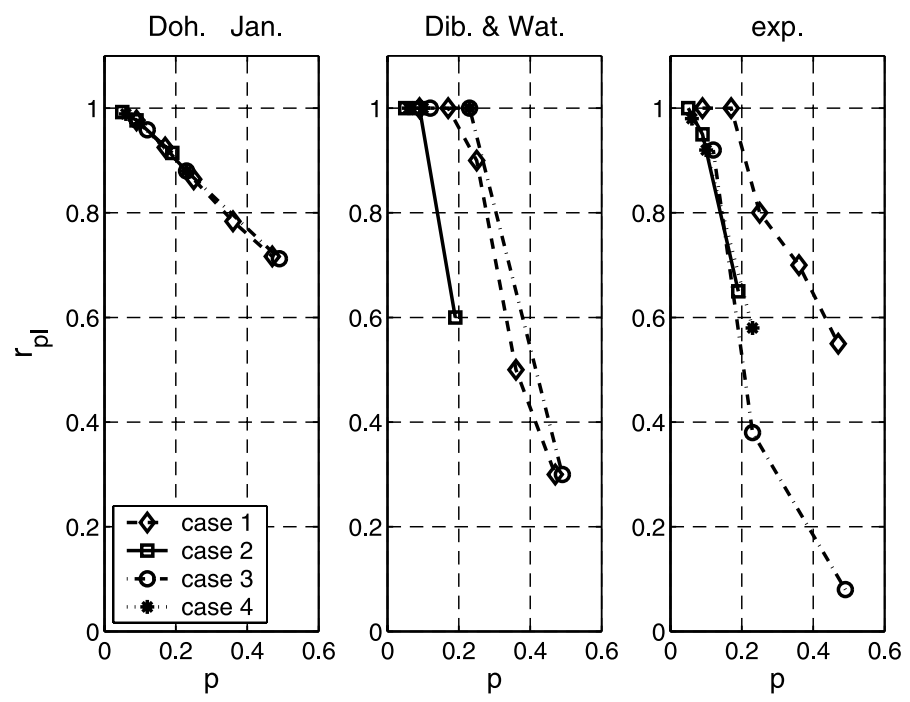

Fig. 15. Phase-lag reduction factor $r_{\mathrm{pl}}$ as a function of phase-lag parameter $p$ (cf. Dohmen-Janssen, 1999; Eqs. (22) and (25)), estimated results of the Dibajnia and Watanabe formula, and experimental data of Dohmen-Janssen.

tions studied, only the Bailard, Dibajnia and Watanabe, and Ribberink formulae can integrate the second order of the Stokes waves. It is therefore expected to obtain constant values for the Bijker and Van Rijn formulae (a slight variation appear due to the computation of the shear stress $\tau_{\mathrm{w}}$ taking into account the asymmetry). This demonstrates the severe limitation of both these formulae, as waves tend to be highly asymmetric in the nearshore environment, particularly near the breaking point and in the surf zone. Hence, as can be seen in Fig. 16a, only the Bailard, Dibajnia and Watanabe, and Ribberink formulae predict sediment transport in the direction of waves although the current direction is opposite (case of undertow). However, it appears that these formulations are not sensitive enough to this parameter if we compare the results with the Dibajnia data. For high values of $r_{\mathrm{w}}$, the use of the
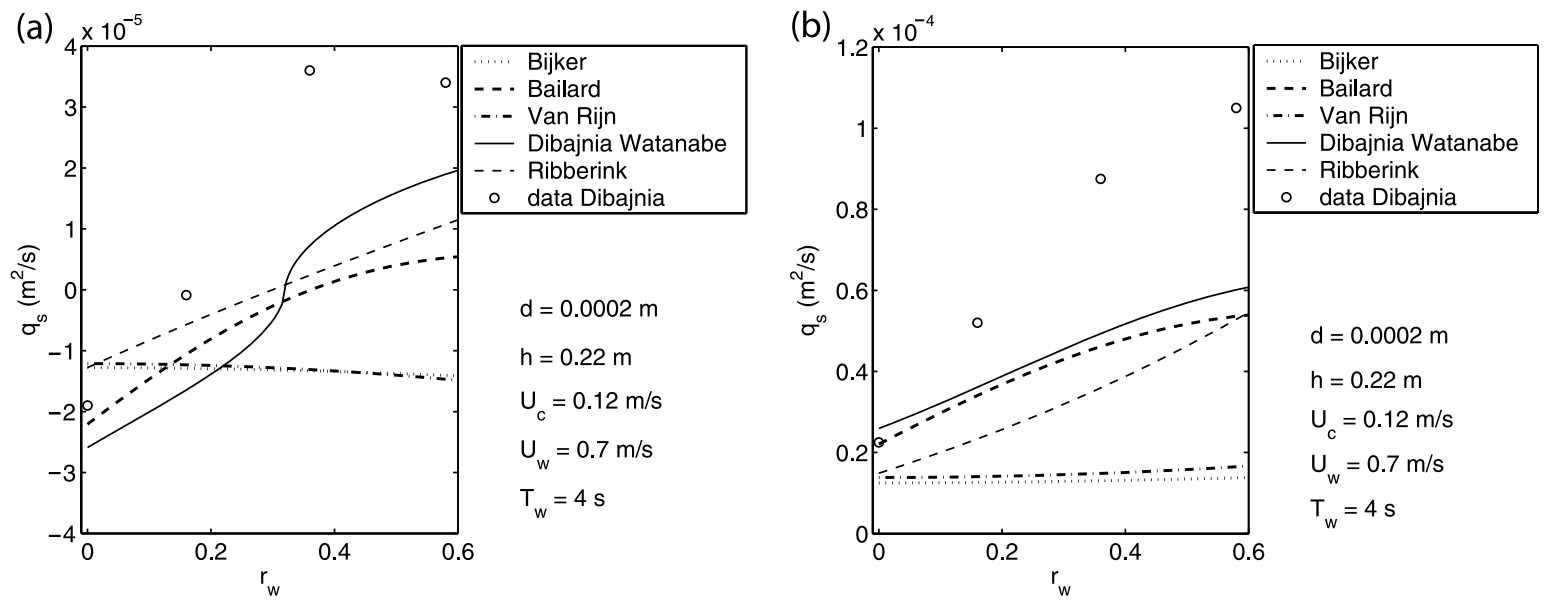

Fig. 16. Influence of wave asymmetry on sediment transport in case of a current in the opposite direction (a) or in the same direction (b). 
second-order theory is not sufficient; the cnoidal theory should then be used. Finally, it can also be observed that asymmetry can play a role in the phase-lag (for high asymmetry, a decrease in the sediment flux is observed in Fig. 16a).

\subsection{Influence of steady current}

The velocity of the current (averaged over the depth in the case of 2DH models) remains one of the fundamental parameters for sediment transport. The first research concerning sediment transport (Du Boys, 1879; Meyer Peter and Müller, 1948; Einstein, 1950; etc.) was performed for a river environment. Thus authors proposed formulae that are mainly functions of the Shields parameter due to the current. Many studies have already been carried out for that specific case. However, the results given by the five formulae studied here are surprisingly scattered. It can be seen in Fig. 17b (case without waves) and mainly in Fig. 17a (case with waves) that the estimation of sand transport can vary by over one order of magnitude depending on the formula.

For instance, for the case without waves (cf. Fig. 17b), the Bijker formula clearly overestimate sediment transport when current velocities are lower than approximately $1.5 \mathrm{~m} / \mathrm{s}$ (this can be explained by its sensitivity to roughness). For strong currents $(>1.3 \mathrm{~m} /$ s), the Ribberink formula underestimates sediment flux due to prevailing suspended load.

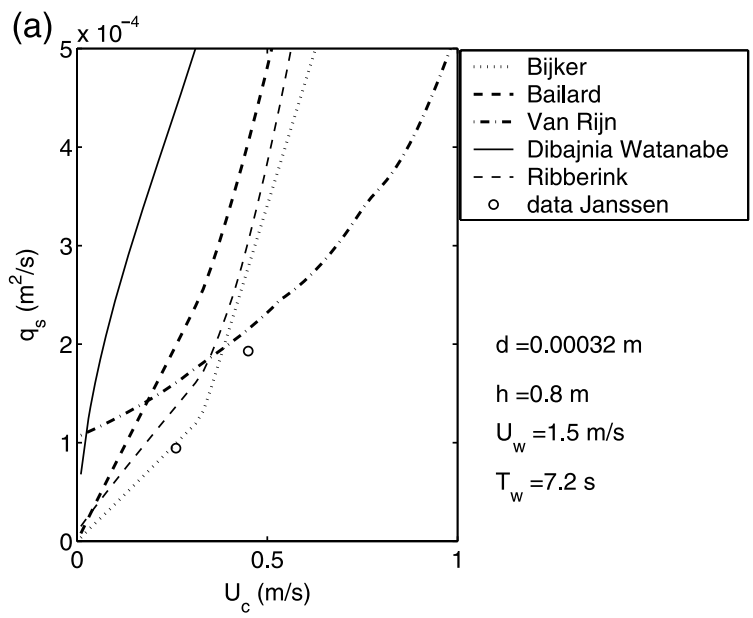

In the case of strong waves $\left(U_{\mathrm{w}}=1.5 \mathrm{~m} / \mathrm{s}\right)$, although there is a lack of experimental data, some remarks are called for. When strong currents are added, a significant scatter is observed in the results. This can be explained by the fact that all these formulae were calibrated with relatively weak currents. According to the authors, no data are available for this kind of case (storm events). The Bailard and Ribberink formulae seems still to overestimate sand fluxes for currents up to $0.5 \mathrm{~m} / \mathrm{s}$. Finally, the Van Rijn formula gives a flux when the current tends towards zero, even if the flux should be zero in the case of sinusoidal waves. This could be explained by the fact that this formula is based on the maximum total shear stress due to the wave-current interaction.

Al Salem (1993) found that net sediment transport is proportional to the velocity moment to the power three. In the case of a sinusoidal wave, we obtain:

$\left\langle U^{3}\right\rangle=U_{\mathrm{c}}^{3}+\frac{1}{2} U_{\mathrm{c}} U_{\mathrm{w}}^{2}$

We should therefore find the slope $a$ of the line as follows:

$a \approx \frac{\Delta q_{\mathrm{s}}}{\Delta\left(\left\langle U^{3}\right\rangle\right)}$

However, in the case of a prevailing current (cf. Fig. 18a and b, where $U_{\mathrm{w}}$ is fixed), straight lines do

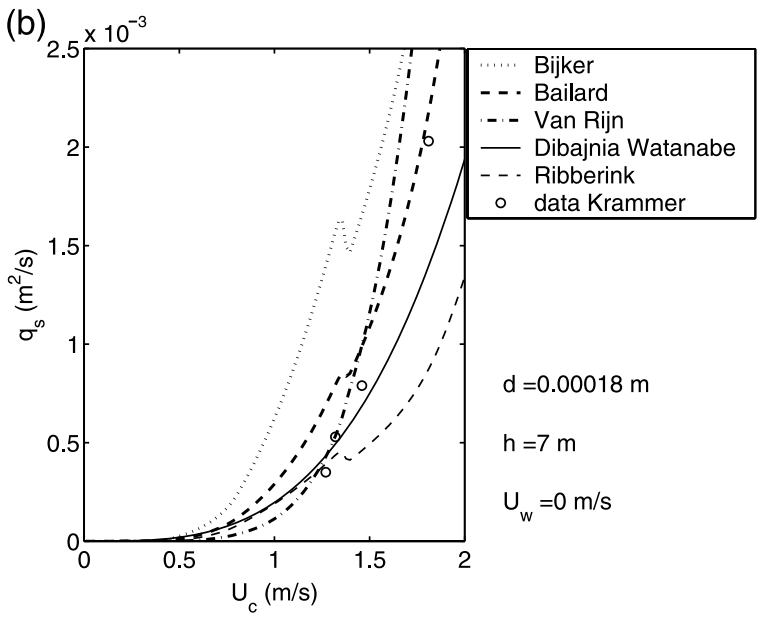

Fig. 17. Influence of current velocity on sediment transport for a case with prevailing waves (a) and a case without waves (b). 
clearly not appear, and strong disparities in the mean slope are found. One explanation is that we take into account total roughness, which is clearly neither linear nor a monotonic function of the current velocity. Thus, for the Dibajnia and Watanabe formula, which does not seem to be very sensitive to roughness, a straight line is observed. Of course, in the case of weak currents and strong waves (cf. Fig. $18 \mathrm{c}$ where $U_{\mathrm{c}}=C t e$ ), phase-lag appears rapidly. Thus, the previous relation cannot be verified any longer, as there is a relative decrease of sand flux when the velocity moment to the power three increases (comparing with the case with a coarser sediment).

(a)

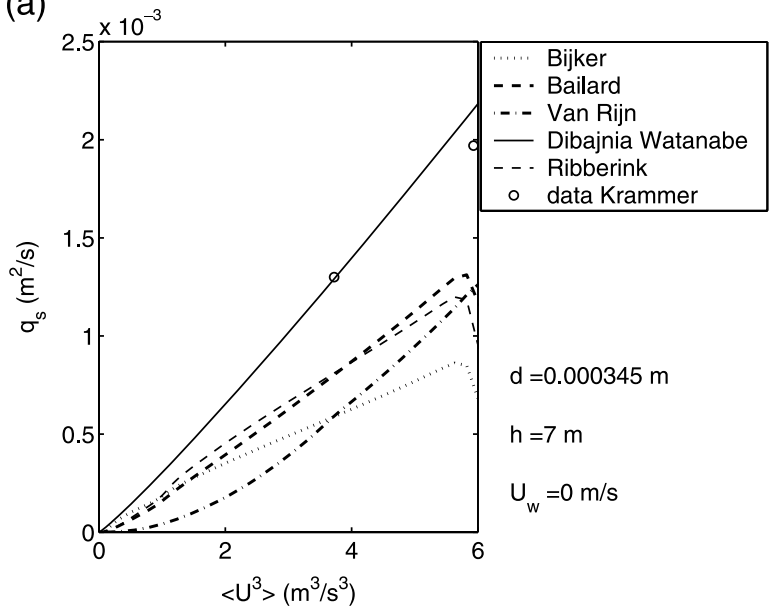

(c)

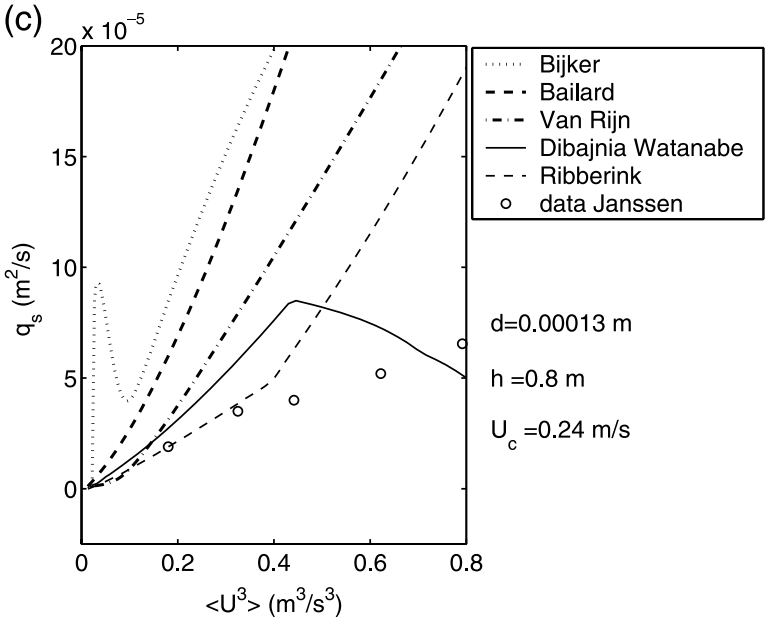

More generally, these five formulations will be compared with all the data available. These data have been cut into four subsets, in relation to grain size diameter (up to $2 \times 10^{-4} \mathrm{~m}$ or more) and in relation to water depth (up to $5 \mathrm{~m}$ or more). Field data (Scheldt and Krammer: current only) are thus separated from flume data (Dibajnia, Alsalem and Janssen: wave-current). Even if the results obtained are approximate (they are summarized in Table 1), they show a correct approach to what they should be and what the formulae give. It is clear that the Bijker formula overestimate sediment flux in the case of fine sediment. It can also be observed that Bailard formula tends to slightly overestimate the slope $a$, whereas the Ribberink formula tends to under-
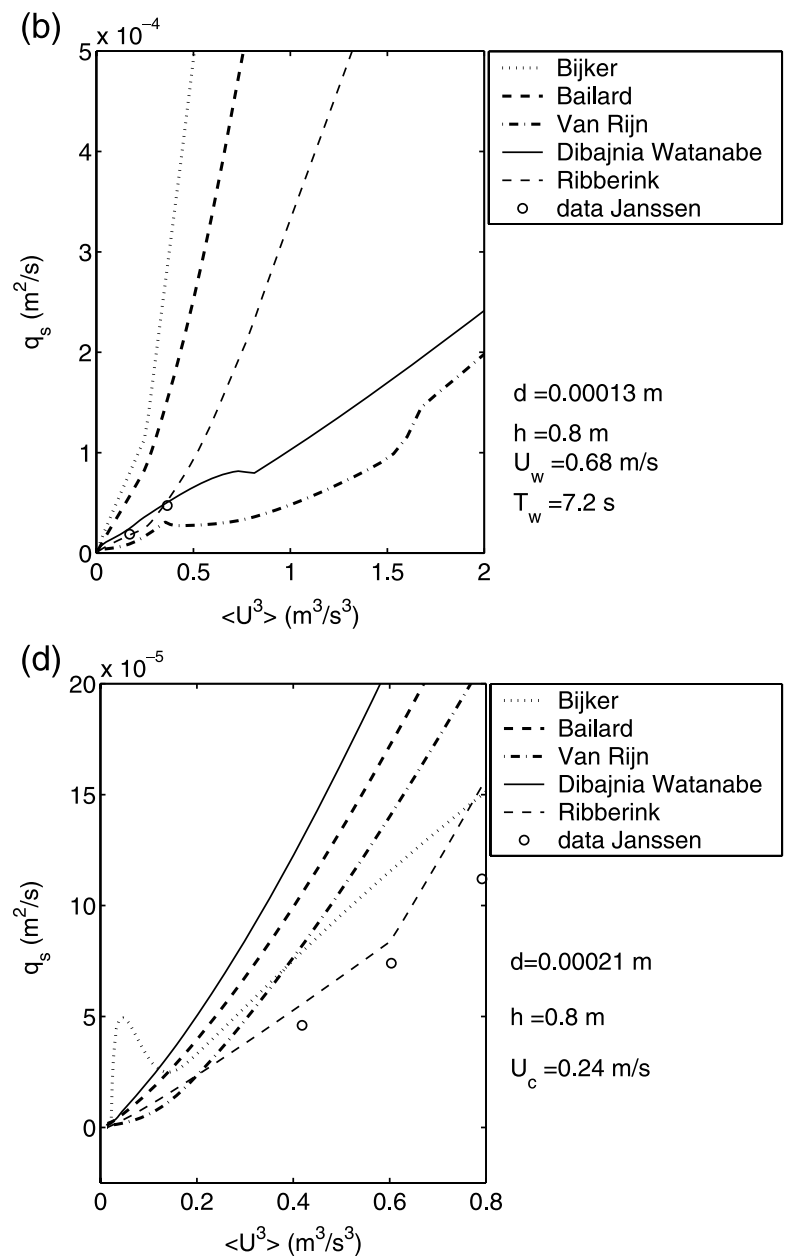

Fig. 18. Relation between sediment flux and velocity moment to the power three $\left\langle U^{3}\right\rangle$ for a case without waves (a), a case with prevailing current (b) and two cases with prevailing waves with fine sediments (c) and coarser sediments (d). 
Table 1

Estimation of the slope $a$ assuming $q_{\mathrm{s}}=a\left\langle U^{3}\right\rangle$ (cf. Eq. (28))

\begin{tabular}{|c|c|c|c|c|}
\hline $\begin{array}{c}\text { Values of "a" } \\
\text { study case }\end{array}$ & $\begin{array}{l}d \leq 2 \times 10^{-4} \mathrm{~m} \\
h>5 \mathrm{~m} \\
\text { (current only) }\end{array}$ & $\begin{array}{l}d>2 \times 10^{-4} \mathrm{~m} \\
h>5 \mathrm{~m} \\
\text { (current only) }\end{array}$ & $\begin{array}{l}d \leq 2 \times 10^{-4} \mathrm{~m} \\
h \leq 5 \mathrm{~m} \\
\text { (wave + current) }\end{array}$ & $\begin{array}{l}d>2 \times 10^{-4} \mathrm{~m}, \\
h \leq 5 \mathrm{~m} \\
\text { (wave + current) }\end{array}$ \\
\hline Experimental & $a_{\mathrm{exp}} \approx 3.5 \times 10^{-4}$ & $a_{\mathrm{exp}} \approx 3.5 \times 10^{-4}$ & $a_{\mathrm{exp}} \approx 1.0 \times 10^{-4}$ & $a_{\mathrm{exp}} \approx 1.5 \times 10^{-4}$ \\
\hline Bijker & $\begin{array}{l}a \approx 1.5 \times 10^{-4} \\
a / a_{\exp } \approx 0.4\end{array}$ & $\begin{array}{l}a \approx 5.0 \times 10^{-4} \\
a / a_{\exp } \approx 1.4\end{array}$ & $\begin{array}{l}a \approx 1.0 \times 10^{-3} \\
a / a_{\mathrm{exp}} \approx 10\end{array}$ & $\begin{array}{l}a \approx 2.0 \times 10^{-4} \\
a / a_{\exp } \approx 1.3\end{array}$ \\
\hline Bailard & $\begin{array}{l}a \approx 2.0 \times 10^{-4}, \\
a / a_{\exp } \approx 0.6\end{array}$ & $\begin{array}{l}a \approx 4.0 \times 10^{-4}, \\
a / a_{\exp } \approx 1.1\end{array}$ & $\begin{array}{l}a \approx 7.0 \times 10^{-4} \\
a / a_{\exp } \approx 7\end{array}$ & $\begin{array}{l}a \approx 3.0 \times 10^{-4}, \\
a / a_{\exp } \approx 2\end{array}$ \\
\hline Van Rijn & $\begin{array}{l}a \approx 2.0 \times 10^{-4}, \\
a / a_{\exp } \approx 0.6\end{array}$ & $\begin{array}{l}a \approx 5.0 \times 10^{-4}, \\
a / a_{\exp } \approx 1.4\end{array}$ & $\begin{array}{l}a \approx 1.0 \times 10^{-4}, \\
a / a_{\exp } \approx 1\end{array}$ & $\begin{array}{l}a \approx 2.5 \times 10^{-5}, \\
a / a_{\exp } \approx 0.2\end{array}$ \\
\hline Dibajnia-Watanabe & $\begin{array}{l}a \approx 3.5 \times 10^{-4}, \\
a / a_{\exp } \approx 1\end{array}$ & $\begin{array}{l}a \approx 2.5 \times 10^{-4}, \\
a / a_{\exp } \approx 0.7\end{array}$ & $\begin{array}{l}a \approx 1.0 \times 10^{-4}, \\
a / a_{\exp } \approx 1\end{array}$ & $\begin{array}{l}a \approx 2.5 \times 10^{-4}, \\
a / a_{\exp } \approx 1.7\end{array}$ \\
\hline Ribberink & $\begin{array}{l}a \approx 2.0 \times 10^{-4}, \\
a / a_{\exp } \approx 0.6\end{array}$ & $\begin{array}{l}a \approx 1.5 \times 10^{-4}, \\
a / a_{\mathrm{exp}} \approx 0.4\end{array}$ & $\begin{array}{l}a \approx 4.0 \times 10^{-4}, \\
a / a_{\mathrm{exp}} \approx 4\end{array}$ & $\begin{array}{l}a \approx 1.5 \times 10^{-4}, \\
a / a_{\mathrm{exp}} \approx 1\end{array}$ \\
\hline
\end{tabular}

estimate it except for cases with waves and fine sediments. Finally, the Van Rijn formula seems to be proportional to the velocity moment to a power up to three when high suspension exists.

Lastly, the coefficient $a$ does not seem to be sensitive to grain size (except for the phase-lag effect), as Dohmen-Janssen (1999) noticed, but $a$ seems to decrease with water depth and/or with the presence of waves following the observed results. Ribberink and Al Salem (1994) have observed that $a$ is an increasing function of the wave period.

\section{Conclusions}

\subsection{Remarks on influences of the different parameters}

Base on all the comparisons carried out in this study, recommendations concerning the use of these formulae can be given depending on the field in which they are to be used. From a purely numerical point of view, it can be pointed out that the Van Rijn formulae call for longer computation times due to the need to compute the integral over the depth of the suspended load.

\subsubsection{Grain size}

The grain size diameter plays an important role in estimating sediment flux (via roughness, settling velocity, etc.). But no formula seems to give satisfactory behaviour with respect to the grain size (see Table 2).

In the case of coarse sediments, sand transport should decrease with the size of the sand until a critical value is reached where there is no transport.
Only the Van Rijn and Ribberink formulae take into account a critical value for the Shields parameter. With the Bailard formula, even though sediment transport does not tend towards zero, it tends towards negligible values in terms of mid-term morphodynamics. Indeed, the critical value of the shear stress seems to be unnecessary for most of the cases.

On the other hand, the Bijker formula even estimates an increasing sediment flux for coarse sand due to its sensitivity to roughness. Roughness is thus a factor too in uencial for the Bijker formula. As total roughness is very difficult to estimate accurately, the Bijker formula is not recommended for grain sizes over $1 \mathrm{~mm}$ (cf. Section 3.1).

In the same way, the Dibajnia and Watanabe formula is not accurate concerning the grain-size dependence except for the specific case of high sheet flow. Some modifications of this formula presented by da Silva and Temperville (2000) and Silva (2001) have improved its behaviour mainly by integrating a friction coefficient in the terms of $\Omega_{\mathrm{c}}$ and $\Omega_{\mathrm{t}}$, and calibrating the ripple parameter $\omega_{\mathrm{cr}}$ towards data. At last, while the Ribberink formula is less sensitive to roughness, its behaviour in relation to grain size seems to be too insensitive since it takes into account the bed load only.

\subsubsection{Waves}

In the case of very fine sediments, the results diverge noticeably. It is clear that for a prevailing current, the suspended load (and hence the total load) increases with decreasing grain size. However, the order of magnitude of suspended load for fine sediments is very different from one formula to another. 
Table 2

Calculated transport rate in the range of $50 \%$ and $200 \%$ of measured transport rate $(\mathrm{Cc} 50, \mathrm{Cw} 50)$ and assessed physical behaviour of the different sediment transport formulae in relation to the studied parameters $(++$ : excellent, + : good, $-:$ poor, $--:$ unsuitable)

\begin{tabular}{|c|c|c|c|c|c|}
\hline Parameters & Bijker & Bailard & Van Rijn & Dibajnia-Watanabe & Ribberink \\
\hline \multicolumn{6}{|l|}{ Global estimations } \\
\hline Cc50 (strong current) & $66 \%$ & $82 \%$ & $70 \%$ & $84 \%$ & $60 \%$ \\
\hline Cw50 (wave + current) & $18 \%$ & $35 \%$ & $45 \%$ & $48 \%$ & $45 \%$ \\
\hline \multicolumn{6}{|l|}{ Varying diameter $d$} \\
\hline$U_{\mathrm{c}} \gg U_{\mathrm{w}}$ & + & + & + & -- & -- \\
\hline$U_{\mathrm{c}}+U_{\mathrm{w}}$ & - & + & ++ & - & - \\
\hline$U_{\mathrm{c}} \ll U_{\mathrm{w}}$ & -- & -- & - & + & + \\
\hline \multicolumn{6}{|l|}{ Varying orbital velocity $U_{\mathrm{w}}$} \\
\hline$d<0.2 \mathrm{~mm}$ & -- & -- & - & + & - \\
\hline$d>0.2 \mathrm{~mm}$ & + & + & + & + & + \\
\hline Varying wave period $T_{\mathrm{w}}$ & -- & -- & -- & ++ & -- \\
\hline Varying wave asymmetry $r_{\mathrm{w}}$ & -- & + & -- & + & + \\
\hline \multicolumn{6}{|l|}{ Varying steady current $U_{\mathrm{c}}$} \\
\hline$U_{\mathrm{w}} \gg U_{\mathrm{c}}$ & - & - & + & + & + \\
\hline$U_{\mathrm{w}}=0$ & + & + & + & + & - \\
\hline
\end{tabular}

Computations of suspended load with the Bijker formula are very sensitive to current while with the Bailard and Van Rijn formulae are more sensitive to waves. On the other hand, the Dibajnia and Watanabe formula, which does not compute suspended load and bed load separately, is not sensitive to fine sediments. It therefore seems to behave poorly for that specific case. Yet, when waves dominate, only this formula can take into account the phase-lag effect, and is thus able to predict sediment transport opposite to the current direction for extreme cases. This is particularly important in the surf zone where the current ("undertow") is opposite to the incident waves. We therefore recommend the Dibajnia and Watanabe formula when waves dominate (especially for large sheet flow where phase-lag occurs), and the Van Rijn and Ribberink formulae for wave-current interaction. Finally, for the specific cases where phase-lag occurs, a linear relation seems to link the phase-lag correction factor $r_{\mathrm{pl}}$ and the phase-lag parameter $p$.

The wave asymmetry (used for the second-order Stokes waves) seems to be an important parameter. Waves become more and more asymmetric when approaching the coast. This factor is important not only from a quantitative point of view but also from a qualitative one. Indeed, wave direction has a strong influence on the direction of sediment transport if we take into account asymmetry. Only the Bailard, Dibajnia and Watanabe, and Ribberink formulae account for this parameter, and then only those formulae can be used in a nearshore morphodynamic model. The Bijker and Van Rijn formulae can only be used to estimate longshore sediment transport rate. Van Rijn (1998, Appendix A) proposed a wave-related component for the suspended load that he adds in his Coastran model, but that expression involves significant uncertainties.

\subsubsection{Current}

Al Salem (1993) suggested that sediment flux is proportional to the velocity moment to the power three. This relation seems to be valid except when phase-lag occurs. However, taking into account total roughness slightly complicates the estimation of the slope $a$ as roughness is not a linear or monotonic function of $U^{3}$. The results obtained are widely scattered depending on the formula. Moreover, it seems that the coefficient $a$ is a function of water depth and/or wave orbital velocity and period. Also, it could be stated that the Bailard, Ribberink, and above all the Bijker formulae tend to overestimate this coefficient for wave-current cases.

\subsection{The use of sediment transport formulae}

To conclude, various recommendations have been given regarding the use of these different formulae in relation to the various parameters studied. The recommendations are summarized in Table 2. Regarding global estimations for a large range of data, except for the Bijker formula, similar results are obtained for 
wave and current interaction. Nevertheless, some formulae show non-physical behaviour in relation to parameters which are mainly the grain size and the wave asymmetry (and with lesser consequences, the wave period). At last, for a morphodynamic model of the nearshore zone, the Bijker and Van Rijn formulae should not be used as they integrate only the currentrelated sediment transport.

\section{Acknowledgements}

The major part of the research underlying this paper is being carried out in the Coastal Morphology Task Group of the PNEC programme supported by the French Government and in the HUMOR programme supported by the European Community.

\section{References}

Al Salem, A., 1993. Sediment transport in oscillatory boundary layers under sheet flow conditions. PhD thesis, Delft Hydraulics, The Netherlands.

Bagnold, R., 1963. An approach of marine sedimentation. In: Hill, M.N. (Ed.), The Sea, vol. 3. Interscience, New York, pp. 507-528.

Bagnold, R., 1966. An approach of sediment transport model from general physics. US Geol. Survey Prof. Paper 422-I.

Bailard, J., 1981. An energetics total load sediment transport model for a plane sloping beach. J. Geophys. Res. 86 (C11), $10938-10954$.

Bailard, J., Inman, D., 1981. An energetics bedload model for a plane sloping beach: local transport. J. Geophys. Res. 86 (C11), $10938-10954$

Bijker, E., 1968. Littoral drift as function of waves and current. 11th Coastal Eng. Conf. Proc. ASCE, London, UK, pp. 415-435.

Camenen, B., Larroudé, P., 2000. Numerical comparison of sediment transport formulae. Sandwave Dynamics Workshop, Lille, France, pp. 37-42.

da Silva, P., Temperville, A., 2000. Prédiction du débit sédimentaire à l'aide de la formule de Dibajnia and Watanabe. VIème journées nationales Génie Civil-Génie Côtier, Caen, France, pp. 237-248.

Dibajnia, M., 1995. Sheet flow transport formula extended and applied to horizontal plane problems. Coast. Eng. J. Jpn. 38 (2), 178-194.

Dibajnia, M., Watanabe, A., 1992. Sheet flow under nonlinear waves and currents. Coast. Eng., 2015-2029.

Dohmen-Janssen, M., 1999. Grain size influence on sediment transport in oscillatory sheet flow, phase-lags and mobile-bed effects. PhD thesis, Delft University of Technology, ISBN 90-90129294, The Netherlands.

Du Boys, P., 1879. Le rhône et les rivières à lit affouillable. Ann. Ponts Chaussées 18 (5), 171-195 (in French).
Einstein, H., 1950. The bed-load function for sediment transportation in open channel flows. Technical Report 1026.

Einstein, H., 1972. In: Meyer, R.E. (Ed.), A basic description of sediment transport on beaches, waves on beaches and resulting sediment transport. Academic Press, New York, pp. 29-34.

Frijlink, H., 1952. Discussion des formules de débit solide de Kalinske, Einstein et Meyer-Peter and Muller compte tenue des mesures récentes de transport dans les rivières néerlandaises. 2nd Journal Hydraulique, Société Hydraulique de France, pp. 98-103. In French.

King, D., Seymour, R., 1982. State of the art in oscillating sediment transport models. 17th Coastal Eng. Conf. Proc., pp. 371-385.

Madsen, O., Grant, W., 1976. Sediment transport in the coastal environment. Number 209, M.I.T. Ralph M. Parsons Lab.

Meyer-Peter, E., Müller, R., 1948. Formulas for bed-load transport. Rep. 2nd Meet. Int. Assoc. Hydraul. Struc. Res., Stockholm, Sweden., pp. 39-64.

Ribberink, J., 1998. Bed-load transport for steady flows and unsteady oscillatory flows. Coast. Eng. 34, 52-82.

Ribberink, J., Al Salem, A., 1994. Sediment transport in oscillatory boundary layers in cases of rippled beds and sheet flow. J. Geophys. Res. 99 (C6), 707-727.

Ribberink, J., Chen, Z., 1993. Sediment transport of fine sand under asymmetric oscillatory flow. Delft Hydraulics, Report H840, Part VII, The Netherlands.

Silva, P., 2001. Contribution to the study of the morphodynamic in coastal region. $\mathrm{PhD}$ thesis, University of Aveira, Portugal. In Portuguese.

Soulsby, R., 1995. The "Bailard" sediment transport formula: comparison with data and models. In: Stive, M., de Vriend, H., Fredsøe, J., Hamm, L., Soulsby, R., Teisson, C., Winterwerp, J. (Eds.), Advances in Coastal Morphodynamics, Delft Hydraulics, The Netherlands. ISBN 90-9009026-6.

Soulsby, R., 1997. Dynamics of marine sands, a manual for practical applications. Thomas Telford, ISBN 0-7277-2584X, H.R. Wallingford, England.

Van Rijn, L., 1984. Sediment Transport: Part 1. Bed Load Transport; Part 2. Suspended Load Transport; Part 3. Bed Forms and Alluvial Roughness, Vol. 110. ASCE.

Van Rijn, L., 1989. Handbook Sediment Transport by Currents and Waves, Vol. Report H461. Delft Hydraulics.

Van Rijn, L., 1993. Principles of Sediment Transport in Rivers, Estuaries and Coastal Seas. Aqua Publications, The Netherlands.

Van Rijn, L., 1998. Principles of Coastal Morphology. Aqua Publications, The Netherlands.

Van Rijn, Davies, der Graff, V., Ribberink (Eds.), 2001. Sedmoc: Sediment Transport Modelling in Marine Coastal Environments. Aqua Publications, Amsterdam, The Netherlands. ISBN 90800346-4-5.

Voogt, L., Van Rijn, L., Van den Berg, J., 1991. Sediment transport of fine sand at height velocities. J. Hydrol. Eng. 117 (7), $869-890$.

Wikramanayake, P., Madsen, O., 1991. Calculation of movable bed friction factors. Technical report, Massachusetts Inst. of Tech., Cambridge, MA. 105 pp.

Wilson, K., 1987. Analysis of bed-load motion at high shear stress. J. Hydrol. Eng. 113 (1), 97-103. 